\title{
"Functional Outcome in Exchange Nailing with Autogenous Cancellous Bone Graft for Aseptic Nonunion of Femoral Shaft: A Study in Pabna Medical College Hospital, Pabna, Bangladesh"
}

\author{
Md. Masudur Rahman ${ }^{*}$, Md. Mohiuddin Aslam², Tapas Kumer Talukder ${ }^{3}$, Md. Nazrul Islam ${ }^{4}$
}

${ }^{1}$ Assistant Professor, Department of Orthopaedic Surgery, Pabna Medical College, Pabna, Bangladesh

${ }^{2,3}$ Assistant Professor, Department of Orthopaedic Surgery, Shaheed Ziaur Rahman Rahman Medical College, Bogura, Bangladesh

${ }^{4}$ Assistant Registrar, Department of Orthopaedic Surgery, Shaheed Ziaur Rahman Rahman Medical College, Bogura, Bangladesh

DOI: $10.36347 /$ sjams.2020.v08i06.029

| Received: 02.06.2020 | Accepted: 19.06.2020 | Published: 26.06.2020

*Corresponding author: Md. Masudur Rahman

\section{Abstract}

Original Research Article

Femoral shaft non-union is a functional and economical challenge for the patient as well as a treatment dilemma for the surgeon. The Association for Osteo-synthesis (AO)' as a means of preventing the development of fracture disease and early recovery. Intramedullary (IM) nailing is the gold standard for the management of femoral shaft fractures. To find out the Functional outcome in exchange nailing with autogenous cancellous bone graft for aseptic nonunion of femoral shaft. From July 2015 to June 2017, more than 30 patients of femoral shaft aseptic nonunion were treated with this technique at Pabna Medical College Hospital and clinics in Pabna, Bangladesh. 21 patients were finally recorded for study. Among them 1 (one) patient was lost after 04 weeks before fracture healing. Culture of the 1 st reaming materials revealed growth in 2 cases. So, final outcome, analysis and test of significance were done with 18 patients. Mean age 41.95 Years; SD \pm 13.11 ; Male: Female $=3.3: 1$ Among 18 fractures nonunion, 15 fractures $(83.33 \%)$ were united and 3 fractures (16.67\%) were not united after exchange nailing with autogenous bone graft in aseptic condition. Confidence Interval at $95 \%$ level $66.08 \%-100 \%$. Mean union time was $26.00 \pm 4.5$ weeks where $95 \%$ confidence interval was $23.49 \pm 28.51$ weeks including both static and dynamic mode of fixation. In static mode mean union time were $29.33 \pm 3.01$ weeks whereas in early dynamic it was $21.33 \pm 1.63$ weeks. It was also calculated that after late dynamization mean union time was 28.67 \pm 2.309 weeks. Among complications unacceptable Angle deviation $5.6 \%$, Limb length discrepancy 5.6\%, Pain -Swelling 5.6\%, Infection 11.12\%, Joint motion restriction 5.6\%, Implant failure $5.6 \%$. There was a strongly positive correlation between age and union time; that means more the age more the union time. In this study, it was found that smoking and NSAIDs both had significant relation $(\mathrm{p}<0.05)$ with fracture union time. Highly strong $(+)$ ve correlation was found between non union period and union time after exchange nailing. Final outcome according to modified Thoresen's score was Satisfactory $78 \%$; according to modified Silvia's score was $10.83 \pm 2.203$. In fracture united cases postoperative SF-MFAS Function Index was achieved $2.5 \pm 1.7$ and Bother index was achieved $1.89 \pm 1.08$. There was a highly significant $(\mathrm{p}<0.001)$ difference between pre operative and post operative functional outcome after exchange nailing with open bone graft as a whole. Exchange nailing with autogenous cancellous bone graft seems to be an effective method of treatment in femoral shaft nonunion after intramedullary nailing. It provides a good scope to reinforce the optimum mechanical stability by a larger diameter nail and locked if necessary; as well as biological stimulation by reaming and open bone grafting.

Keywords: Intramedullary (IM), Femoral shaft fractures, Graft for aseptic nonunion, Outcome.

Copyright @ 2020: This is an open-access article distributed under the terms of the Creative Commons Attribution license which permits unrestricted use, distribution, and reproduction in any medium for non-commercial use (NonCommercial, or CC-BY-NC) provided the original author and source are credited.

\section{INTRODUCTION}

Femoral shaft non-union is a functional and economical challenge for the patient as well as a treatment dilemma for the surgeon [1]. After the advent of skeletal radiography internal fixation of fractures has been proposed by 'The Association for Osteo-synthesis (AO)' as a means of preventing the development of fracture disease and early recovery [2]. Intramedullary (IM) nailing is the gold standard for the management of femoral shaft fractures [3-6]. It has lower rates of infection and non-union than plate fixation [7-9]. As a load sharing implant, it allows earlier weight bearing after surgery [10-11]. Closed intramedullary interlocking is preferred to open procedures to preserve periosteal blood supply and minimize surgical trauma adjacent to the fracture. ${ }^{12}$ Open interlocking is often used in developing countries due to various constrains[13-15]. Unlocked nailing (K-nail)is still 
useful for the management of non-comminuted isthmus fractures of femur[16]. But recently, the incidence of femoral shaft nonunion after intramedullary interlocking nailing is higher (20\% to50\%) [17-19] in both close and open method than previously reported (0\% to $10 \%$ in close method; [3, 20-23] $0 \%$ to $20 \%$ in open interlocking, up to $25 \%$ in k-nail fixation of isthmus fracture [15]). This may be due to the greater likelihood of survival of the poly traumatized patient and improved limb salvage techniques. It may also be influenced by severity of the injury, damage to the surrounding soft tissues, inadequate initial fixation, and demographic characteristics of the patient, advanced age, medical co-morbidities including nicotine and excessive NSAIDs use[1]. Early weight bearing has been reported to be safe and facilitate fracture healing. Exchange nailing can ensure early ambulation and fulfill concept of fast track orthopedics with excellent functional outcome [30-36]. Closed reamed exchange nailing was reported to be the best treatment for nonunion of femoral shaft fractures but the entire non-union could not be treated with only closed exchange nailing [28]. A significant number of patients who undergo closed reamed exchange nailing will require additional procedures to achieve fracture healing like isolated open bone graft, nail dynamization and compression plating etc[18]. It was noted that patients subjected to an open bone grafting procedure during exchange nailing united more quickly (mean union time 24.6 weeks) than closed technique (mean union time 36.2 weeks). But this did not achieve statistical significance $(p=0.14)$ [37]. Another study showed union rate in both methods was $100 \%$; but union period for the closed technique was $4.0 \pm 0.6$ months, whereas it was $5.1 \pm 0.8$ months for the open technique [38]. Success rates of exchanged reamed IM nailing by either close or open method are as high as $100 \%$ have been reported [39]. In contrast, a recent study reported a $47 \%$ failure rate for exchange reamed femoral nailing; which demands further evolution of this procedure[18] Moreover, non-union treatment increases in complexity as the components of the non-union increases. When any deformity or broken intramedullary nail is present, fracture site opening is mandatory. When atrophic non-union present excision of all necrotic and sclerotic bone, decortications must be carried out and extra cortical cancellous bone grafts should be added [40]. In hypertrophied non-union, callus loss its osteogenicity after a certain period [7], so autogenous bone graft is a good option [39]. Fracture site sub periosteal decortications and autogenous bone grafting by Judet and Patel in 1972 reported excellent result which was re-evaluated by Wu Oiang in 2001 in China and reviewed by Ricardo J Pacheco in 2004 in UK and describe this procedure as local stimulation for union [29, 41, 42]. Due to non-availability of image intensifier fluoroscopy in most of the centers of developing countries; open exchange nailing with autogenous bone graft are commonly practiced. But evolution and records of these procedures are minimum [14]. Considering all these facts, we have done a study to evaluate the result of exchange nailing with autogenous bone graft in aseptic femoral shaft nonunion, including assessment of functional outcome and influence of other factors on non-union. These relatively poor results have sparked interest in the development of newer implants, techniques and biologic agents [24-26].

\section{Aseptic non-union treatment should follow three principles}

a. Realignment b.Stabilization c.Stimulation[27]

There are several surgical options for treating femoral shaft aseptic non-union which are initially treated with intramedullary nails

Exchange nailing-kuntscher`s nail to kuntscher's nail or kuntscher's nail to interlocking or interlocking to interlocking with or without autogenous bone grafting according to need for fracture stability [1].

1. Plate Osteosynthesis [1]

2. Plate augmentation and bone grafting leaving the nail in situ [28].

3. Osteoperiosteal decortications with bone graft and either internal fixation using plates/intramedullary rods or external skeletal fixation [29].

4. External fixator-Ilizarov technique[1]

5. Adjuvant treatment alternatives- Nail dynamization, electrical stimulation, extra cortical cancellous bone graft, bone marrow aspirate and the application of newer biologics such as BMPs(recombinant human BMP-7) etc.

Exchange nailing refers to the practice of removing an already present medullary implant, reaming the medullary canal to a larger diameter and inserting a larger-diameter nail including inter locking if needed. This technique stimulates bone union mechanically and biologically. The biologic stimuli that promote union following exchange nailing include the deposition of autogenous bone graft at the nonunion site and the stimulation of a periosteal healing response through the process of femoral canal reaming [1].

\section{REVIEW LITERATURES}

It was recorded that Aztecs used wooden intramedullary nails 500 years ago. Early orthopedic surgeons such as Senn, Lambotte and Hey Grooves investigated the use of Ivory, bone and metallic nails [12]. Intramedullary nail fixation of femoral shaft fractures with the use of clover shaped was popularized by a German Orthopedic Surgeon, Kuntscher during the $2^{\text {nd }}$ World War. Though the principle was well known as Lambotte of Antwerp in 1913 and Hey Grooves of Bristol in 1918 who used similar methods during the $1^{\text {st }}$ World War, but lack of inert metals was major handicap [2]. Advancement in closed surgical techniques and improvements in implant design including various type of interlocking offer good control of limb length and 
rotational alignment $[3,4,5]$. Rates of non-union of between $1 \%$ and $25 \%$ have been described after intramedullary nailing including $\mathrm{K}$-nail, interlocking closed or open; but currently it is up to 50\%[3-6,17-19]. Christensen N on 1973[55]; Nahigian SH, Rascher JJ, Farrall JP on 1975[56], Kempf I, Grosse A, Rigant P on 1986[57] Wu cc, Shih CH on 1991 [58] described intramedullary nailing for the treatment of delayed union and non-union of femoral fractures but rarely distinguished between patients undergoing nail exchange and those undergoing nail stabilization following failure of another method such as plate fixation. Most of these early studies demonstrated high rates of osseous union, but the studies were heterogenous in nature and the precise details of the nailing procedure, such as the nail diameter and the reaming technique, were rarely discussed. In 1972, Olerud and Karlstrom [59] reported an exchange of an intramedullary nail for a larger-diameter nail in the treatment of a non-union of the tibia. The following year, Christensen reported on nail exchange in nine patients who were part of a series of thirty-five patients treated with intramedullary nailing of a non-union of the femur or tibia. The reported union rate at that time in the entire series was $100 \%$ [55]. Fracture site sub periosteal decortications and extra cortical bone grafting along with intramedullary rod in femoral shaft non union was done by Judet and Patel in 1972; reported excellent result [29]. Oh et al. $1^{\text {st }}$ described a series of fifteen femoral non-unions in which twelve were treated with closed nail exchange; two patients had active infection at the time of nail exchange. All patients had osseous union [56]. Throughout the 1980s and early 1990s, several authors reported other examples of nail exchange for treatment of non-union within larger series of patients undergoing intramedullary nailing following failure of other treatment methods [23, 57, 60]. On 1984 Harper reported that sixteen patients with femoral nonunion had osseous union following intramedullary nailing. Eight patients in the series had undergone nail exchange (five with concomitant open autogenous bone-grafting); six of the eight had osseous union and one additional patient had osseous union after a second exchange to a larger diameter nail[60]. On $1986 \mathrm{Web}$ et al. described the results of intramedullary nailing of femoral non-union in 105 patients, forty nine of whom had been previously treated with intramedullary nailing of the fracture. The overall rate of osseous union following intramedullary nailing for the entire series was $96 \%$, but no specific details were given for those forty nine patients treated with nail exchange [23]. On the same year 1986 Klemm reported a series of thirty six patients in whom infected femoral or tibial nonunion had been treated with nail exchange, continuous irrigation suction drainage and antibiotic therapy. All sixteen infected femoral non-unions healed and nineteen of twenty infected tibial non-unions healed[61]. In a series of sixty-six lower extremity nonunions, Kempf et al. found that four of six femoral nonunions and nineteen of twenty one tibial non-unions united following nail exchange [57] Wu Chi-Chuan, Chen, Wen-Jer on 1997 had done a comparative study to see the effects of closed and open bone grafting technique in exchange nailing for femoral shaft aseptic non-unions [38]. Out of thirty five patients sixteen treated by the closed technique and nineteen treated by the open technique. All thirty five non-unions healed, for a union rate of $100 \%$. The union period with the closed technique was shorter than with the open technique $(4.0 \pm 0.6$ months vs. $5.1 \pm 0.8$ months; $\mathrm{p}<$ $0.01)$. The operating time with the closed technique was also significantly shorter than with the open technique (36 \pm 7 minutes vs. $58 \pm 14$ minutes; $\mathrm{P}<0.01$ ). There was no significant difference in other parameters [38]. They concluded that the open bone grafting technique should be used as the second choice when the closed technique is inadequate (e.g. if there is rotational or angular misalignment of several bone defects etc.). Yet, either technique can achieve a very satisfactory outcome[38]. But on 1999 Furlong A J, Giannoudis PV, et al. reviewed records and radiographs of 25 patients who had a reamed exchange femoral nailing (various type of nail were used) for established aseptic nonunion. Twenty four patients (96\%) united after exchange without the need for an additional procedure. The mean time to union was 29.75 weeks. Patients who had open bone grafting performed at the same procedure tended to unite quicker, but this did not achieve statistical significance $(p=0.14)$. Union times were not affected by smoking habits or nail type. They concluded that the nail type is less important than the biological effects of reaming, bone grafting and dynamization [37]. Hak DJ. LeeSS, Goblet JA. On 2000 reported their investigation on success of exchange reamed femoral nailing in the treatment of femoral nonunion after intramedullary nailing and analysis on factors those may contribute to failure of exchange reamed femoral nailing [17]. They work on 23 patients; all were treated by exchange reamed femoral nailing for their femoral shaft non-union or delayed union. The diameter of the new nail was $1 \mathrm{~mm}$ to $3 \mathrm{~mm}$ larger than that of the previous nail (the majority were $2 \mathrm{~mm}$ larger). The intramedullary canal was over-reamed by 1 $\mathrm{mm}$ more than the diameter of the nail [17]. Most of the nails were statically locked and care was taken to avoid distraction of the non-union site by reverse impaction after distal interlocking was performed or by applying compression with a femoral distracter. Eighteen patients out of twenty three healed without additional procedure $(78.3 \%)$. Of the five patients whose fractures failed to unite after exchange nailing, all were smokers and all had atrophic non-unions. Three of these patients achieved union after subsequent procedures; one after repeat exchange reamed nailing and two after iliac crest bone grafting. Another patient has recently undergone dynamization of her nail. The final patient, who has an atrophic subtrochanteric non-union following multiple operative procedures, has recently undergone repeat exchange nailing combined with iliac crest bone grafting. They also reported that in their series all of the 
eight non-smokers healed after exchange reamed nailing. Only ten of the fifteen smokers (66.7\%) achieved union after exchange reamed nailing $(95 \%$ confidence interval, 43.1 to $90.9 \%$ )[17]. In this article author recited from other author's article about effects of nicotine on the rate and strength of long bone fracture healing. Nicotine has been shown experimentally to affect union rate and fracture callus strength. One mechanism for nicotine's detrimental effect may be a delay and decrease in revascularization of the associated bone graft. Clinical observations have suggested an inverse relationship between smoking and healing in spinal fusion patients. Schmitz et al. reported that the average time to union in closed and grade 1 open tibia fractures was $70 \%$ longer in smokers[17] On 2000 P. Tornetta III, D. Tiburzi reported a prospective randomized comparison of antegrade and retrograde procedures in 68 patients with 69 fractures of the femoral shaft. All nails were inserted after appropriate reaming. There was no difference in operating time, blood loss, and technical complications, size of nail or reamer or transfusion requirements. Pain in the knee was commonly reported by the retrograde group in the period soon after surgery, but resolved in most cases, usually with return of quadriceps strength. At the time of union of the fracture there was no difference in pain in the knee between the two groups. There was no other difference in the outcome of the patients [62]. On 2000 P. V. Giannoudis, D. A. Mac Donald et al. reported their retrospective review article about the influence of various factors including reaming and non-steroidal anti-inflammatory drugs on non-union of the femoral diaphysis. They found no significant relationship between the rate of union and the type of implant, mode of locking, reaming, smoking habit. They found a marked association between non-union and the use of NSAIDS after injury $(\mathrm{P}=0.000001)$ [63] (Table-1). But in subsequent studies it is now established that reaming is essential both in acute fracture and exchange nailing in non-union management [63]. Pihlajama Ki HK, et al. on 2002 stated that autogenous extra cortical bone grafting alone proved to be insufficient in their study [51].

On 2003, Paul A, et al. reported their single centre prospective study of exchange nailing for aseptic non-union of a femoral fracture. They showed that a significant number of non-union required additional procedures to achieve union [65]. On 2003, Canadian Orthopaedic Trauma Society published their report after a multicenter, prospective randomized clinical trial on 224 patients to compare nailing without reaming and nailing with reaming. They concluded that intramedullary nailing of femoral shaft fractures without reaming results in a significant higher rate of non-union compared with intramedullary nailing with reaming [20].

Table 1: review of the literature on contemporary techniques of exchange nailing

\begin{tabular}{|c|c|c|c|c|c|c|}
\hline $\begin{array}{c}\text { Anatomic } \\
\text { Region/Study } \\
\text { Femoral diaphysis }\end{array}$ & $\begin{array}{l}\text { Total } \\
\text { cases }\end{array}$ & $\begin{array}{l}\text { Infection at } \\
\text { Time of } \\
\text { Exchange } \\
\text { Nailing }\end{array}$ & $\begin{array}{c}\text { Bone- } \\
\text { Grafting at } \\
\text { Time of } \\
\text { Exchange } \\
\text { Nailing }\end{array}$ & $\begin{array}{l}\text { Interlocking of } \\
\text { Exchange Nail }\end{array}$ & $\begin{array}{l}\text { Osseous } \\
\text { Union } \\
\text { After One } \\
\text { Exchange } \\
\text { Nailing }\end{array}$ & $\begin{array}{l}\text { Average Time to } \\
\text { Osseous Union } \\
\text { Following } \\
\text { Exchange } \\
\text { Nailing (mo) }\end{array}$ \\
\hline $\begin{array}{l}\text { Wu andChen[38], } \\
1997\end{array}$ & 16 & $0(0 \%)$ & $0(0 \%)$ & $\begin{array}{l}\text { Dynamic (56\%), } \\
\text { unlocked }(44 \%)\end{array}$ & $100 \%$ & 4 \\
\hline $\begin{array}{l}\text { Furlong et al.[37], } \\
1999\end{array}$ & 22 & $0(0 \%)$ & $12(48 \%)$ & $\begin{array}{l}\text { Static }(16 \%) \text { dynamic } \\
(84 \%)\end{array}$ & $95 \%$ & 7 \\
\hline $\begin{array}{l}\text { Hak et al.[17], } \\
2000\end{array}$ & 23 & $5(22 \%)$ & $0(0 \%)$ & $\begin{array}{l}\text { Static }(70 \%) \text { dynamic } \\
(26 \%), \text { unlocked }(4 \%)\end{array}$ & $78 \%$ & 10 \\
\hline $\begin{array}{l}\text { Weresh et al.[18], } \\
2000\end{array}$ & 19 & Not reported & $4(21 \%)$ & $\begin{array}{l}\text { Static }(79 \%) \text { dynamic } \\
(21 \%)\end{array}$ & $53 \%$ & 8 \\
\hline $\begin{array}{l}\text { Wu and Chen[64], } \\
2002\end{array}$ & 36 & $0(0 \%)$ & $0(0 \%)$ & $\begin{array}{l}\text { Static }(14 \%) \text { dynamic } \\
(86 \%)\end{array}$ & $92 \%$ & 4 \\
\hline $\begin{array}{l}\text { Pihlajamaki et } \\
\text { al.[51], } 2002\end{array}$ & 18 & $0(0 \%)$ & $4(22 \%)$ & Not reported & $78 \%$ & $<6$ \\
\hline $\begin{array}{l}\text { Banaszkiewicz et } \\
\text { al.[65], } 2003\end{array}$ & 19 & $0(0 \%)$ & $0(0 \%)$ & $\begin{array}{l}\text { Static }(47 \%) \text { dynamic } \\
(32 \%), \text { unlocked } \\
(21 \%)\end{array}$ & $58 \%$ & 9 \\
\hline
\end{tabular}

On 2004, Ricardo J Pacheco reviewed the management of non-union in trauma and stated that non-union treatment should follow three principles: a) realignment b) stabilization c) stimulation [42]. On 2007, WuCC reported his work to determine effective size of over-reaming. He found that the diameter of the new intramedullary nail should be as large as possible to reinforce the mechanical strength of the repair. The osteogenic potential stimulated by the reaming of cancellous bone graft was similar with over-reaming of $1 \mathrm{~mm}$ and with over-reaming of $2 \mathrm{~mm}$ or more [66]. On 2006-2007, Dr.Sharkar KM did a study on exchange nailing for femoral shaft nonunion by SIGN nail in NITOR, Dhaka. In this study, number of cases was 28; mean age was 40.77 years and male female ratio was $3: 2$. Rate of fracture healing was around $80 \%$, average 
union period was 28.09 weeks. Final outcome was $60.71 \%$ excellent, $21.43 \%$ good, $10.72 \%$ fair, $7.14 \%$ poor according to Thoresen`s score[67]. On 2007 Henn G J et al. worked on a new procedure for femoral shaft nonunion. They introduced plate augmentation and bone grafting for the treatment of femoral shaft non-union, leaving the interlocking intramedullary nail in situ to remove the rotational instability of the fracture fragments. Thirty-one patients with non-union of a femoral shaft fracture, who had been treated with interlocking intramedullary nailing, were examined. Twenty six had been oligotrophic non-union and five were hepervascular. Fortyfive procedures were performed for 31 non-unions; bone grafting for 14; exchange nailing for 13; plate augmentation and bone grafting for 14 and dynamization for 4 cases. The success rate after a single procedure was only $58 \%$. The four dynamization cases failed to unite. Seven of the 13 (54\%) non-union cases treated with nail exchange healed satisfactorily. All cases treated with plate augmentation and bone grafting achieved successful union. The mean period from fracture to union was 20 months. So they concluded only exchange nailing is not always a reliable procedure for treating non-union of femoral shaft fracture. Other procedures might be essential for union [68].

\section{SURGICAL ANATOMY $[69,70,71]$}

The femoral shaft is an essentially a tubular structure, it flares posteriorly along the linea aspera, where its cortical thickness is the greatest. The linea aspera or rough line (Latin) serves as a site of attachment for the fascia. The proximal and distal metaphyseal widening of the tube in the subtrochanteric and the supracondylar regions of the bone results in stress concentrations at these levels. The most prominent features of the femoral shaft are its anterior bow or antecurvatume. Most modern intramedullary nails are prebent, with an average 11 to $12 \mathrm{~mm}$ high arch at their midpoint to accommodate the bow. Straight, stiff implants used in the early years of femoral nailing straightened the shaft, leaving a posterior gap at the fracture site. Straight nails also resulted in fracture comminution and occasionally even perforation of the anterior cortex. The femoral shaft is subjected to major musculature forces that deform the thigh after a fracture. The action of the gluteal musculature that inserts on the greater trochanter abducts the proximal Femur after subtrochanteric and high proximal shaft fractures. These proximal third fractures of the shaft also are flexed and externally rotated by the action of iliopsoas musclesspan.

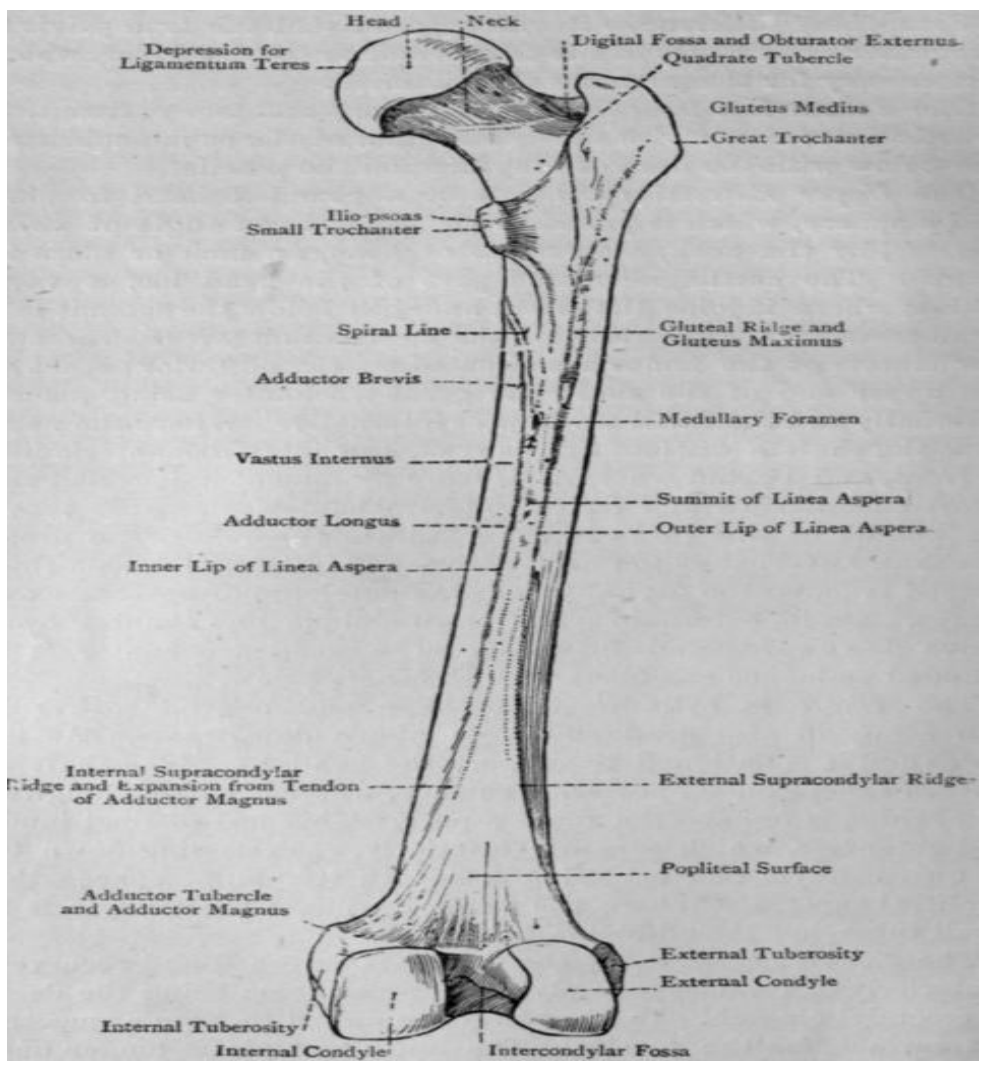

Fig-1: Osteology of Femur

\section{Technical Aspects of Exchange Nailing}

Locked Compared with Unlocked Nails: Many authors have stated that locking screws are often unnecessary in exchange nailing. These authors have proposed that locking of the exchange nail is necessary only when there is instability of the construct or a periarticular nonunion with a small distal or proximal fragment. Some investigators have found no difference in the healing rates or time to union between patients treated with a statically locked nail and those treated 
with a dynamically locked nail. One report showed the time to osseous union to be longer for fractures treated with a statically or dynamically locked exchange nail than for those treated with an unlocked exchange nail.

Unlocked or dynamically locked nails allow gradual compression at the nonunion site during weightbearing and may promote osseous union. Gradual axial compression at the nonunion site can be attained with a statically locked exchange nail if it has slotted interlocking holes. Acute compression at the nonunion site can be obtained intraoperatively either with reverse impaction of the nail or through the use of a femoral destructor.

Slotted Compared with Closed-Section Nails: The optimal bending rigidity and torsional rigidity for an intramedullary nail are unknown. Increasing the rigidity of the nail increases the stability of the nailbone construct, but a nail that is too rigid may increase the risk of comminution at the time of insertion even if the medullary canal is reamed to a diameter $2 \mathrm{~mm}$ larger than that of the nail. Closed-section and open-section (slotted) intramedullary nails have comparable bending rigidities and strengths. The bending rigidity of both types of nails increases proportionately with the fourth powers of the inner and outer radii of the nail, while the strength increases proportionately with the third power of the radius. Thus, a larger-diameter nail provides higher bending rigidity and strength. Clinically, the decrease in bending rigidity attributable to the slot in the nail is small and does not result in a meaningful difference compared with the bending rigidity of a same-sized closed-section intramedullary nail. In contrast, the torsional rigidity of a closed-section nail is many times higher than that of a slotted nail. The torsional rigidity of a closed-section nail increases proportionately with the fourth powers of the inner and outer radii of the nail. Thus, a larger-diameter closedsection nail has higher torsional rigidity. The torsional rigidity of a slotted intramedullary nail, however, increases not with the nail radius but with its circumference and the third power of the wall thickness of the nail. For example, a $10-\mathrm{mm}$ open-section nail with a 2-mm slot would have to have a wall thickness of nearly $4 \mathrm{~mm}$ to have the same approximate torsional rigidity as a $10-\mathrm{mm}$ closed-section nail of the same material with a wall thickness of $1.2 \mathrm{~mm}$. It is difficult to draw any conclusions from the literature or make any recommendations regarding the relative benefits of slotted compared with closed-section nails in exchange nailing of long-bone nonunion.

Nail Diameter: Appropriate exchange-nailing technique includes the insertion of a nail of a larger diameter than the nail being removed. The exchange nail should be at least $1 \mathrm{~mm}$ larger in diameter, but use of a nail that is 2 to $4 \mathrm{~mm}$ larger in diameter greatly increases the stiffness and strength of the construct. The literature contains little definitive information regarding the optimal increase in nail diameter to be used in exchange nailing. The surgeon should be guided by clinical judgment based on the diameter of the medullary canal, the degree of under sizing of the previous nail, the thickness of the cortex, and other osseous and patient characteristics.

Reaming: The literature also provides little definitive information regarding the optimal amount of reaming to be performed during exchange nailing. Court-Brown et al. stated: "Successively larger bits, by $0.5 \mathrm{~mm}$ each time, are used to remove endosteal fibrous tissue until bone is seen on the end of the drill-bit, usually at about a diameter of $1 \mathrm{~mm}$ above the original reaming. More reaming is required if the original nail had been of an inappropriately small diameter." Authors have recommended; over reaming by an amount 1 to 2 $\mathrm{mm}$ greater than the diameter of the new nail being inserted, and the use of sharp reamers, with slow gradual reaming.

Bone-Grafting: The indications for open extra cortical cancellous bone-grafting during exchange nailing remain obscure, and no consensus of opinion can be found in the literature. Several specific options are available when bone-grafting is used in concert with exchange nailing. These include (1) open bone-grafting, whereby the graft material is delivered directly to the nonunion site through an incision overlying it; (2) bone-grafting after refashioning and decortications of nonunion site; (3) intramedullary grafting, whereby the surgeon reinserts the reaming products collected from the reaming flutes back into the medullary canal to the level of the nonunion using a chest tube; and (4) delivery of autogenous iliac crest bone graft to the site of injury through the medullary canal by means of a chest tube. Some authors stated that they added cancellous bone graft by opening the nonunion sites during exchange nailing because of the low healing potential of nonunion and the low morbidity of the bone grafting procedure.

\section{OBJECTIVES}

General

- To evaluate the results of exchange nailing with autogenous cancellous bone graft in aseptic nonunion of femoral shaft.

\section{Specific}

- To calculate the union rate and time period for union.

- To find out complications rate.

- To analyze effects of other factors that may influence fracture healing during this procedure.

- To evaluate the final outcome ( using modified Thoresen`s scoring system [4,14]; modified Silvia`s scoring system[53] and Short-Form Musculoskeletal Function Assessment Survey :SFMFAS [54]) 


\section{Materials \& Methods}

Study design: Quasi experimental (Prospective interventional study with pre and post procedure design).

Study period: $01 /$ 07/2015 to $30 / 06 / 2017$ (24 months) Place of study: Dept. of Orthopaedic surgery, PMCH and clinics in Pabna, Bangladesh.

Sampling population: All patients with clinical and radiological evidence of femoral shaft non-union after intramedullary (IM) nailing (either locked/ unlocked) in acute fracture admitted in Hospitals for re operation.

Sample size: Sample size was calculated by using following statistics

$N=\frac{z^{2} P Q}{d^{2}}$

Here, $\mathrm{Z}$ is the confidence limit, $\mathrm{P}$ is the prevalence rate and $\mathrm{Q}$ is 1-P (or, proportion of persons not suffering from the disease), $d$ is the acceptable standard error and $\mathrm{n}$ is the required sample size.

Disorders of union occur in some 5-10\% of long bone fractures varying with each bone and with different methods of treating acute fractures [74].

$\mathrm{Z}=1.96, \mathrm{P}=0.075$ (taking $7.5 \%$ as prevalence), $\mathrm{Q}=0.925$, $\mathrm{d}=0.05$

So, $\mathrm{n}=\left\{(1.96)^{2} \times 0.075 \times 0.925\right\} / 0.05^{2}=102$

Sample size should increase $10 \%$ due to non-respond that is 112

However in this study 20 patients were studied; due to time and financial constraint. Initial target was to enroll 112 patients, but following operation, majority of the patients were reluctant to follow up visit and that was increased more after $3^{\text {rd }}$ visit (at the end of $10^{\text {th }}$ weeks) when advised for $50 \%$ to one crutch assisted weight bearing. 21 patients were finally recorded for study. Among them 1(one) patient was lost after 14 weeks before fracture healing. Culture of the $1^{\text {st }}$ reaming materials revealed growth in 2 cases. So, final outcome, analysis and test of significance were done with 18 patients.

Sampling technique: Purposive sampling was done according to availability of the patients and strictly considering the inclusion and exclusion criteria.

\section{INCLUSION CRITERIA}

1. Patient age $>18$ years to $<70$ years.

2. Patient with femoral diaphyseal non union; treated by prior IM nailing with or without interlocking, developed nonunion.

3. Aseptic nonunion with $\leq 2 \mathrm{~cm}$ of shortening or $\leq 1$ $\mathrm{cm}$ gap non union.

4. Lax/mobile angular or rotational mal-alignment; that are varus or valgus, internal or external rotation.

\section{EXCLUSION CRITERIA}

1. Patient age $<18$ years and $>70$ years.

2. Patient with pathological fracture.

3. Infective case of nonunion.

4. History of irradiation.

5. Aseptic non union with more than $\geq 2 \mathrm{~cm}$ of shortening, $\geq 1 \mathrm{~cm}$ of gap non union.

6. Patient who developed a nonunion after a rotational osteotomy, closed femoral shortening or lengthening procedure.

7. Patients suffering from Systemic illness like Diabetes, COPD etc.

Follow up: Follow up schedule described in appendices. At least 1 year was targeted to evaluate final functional outcome where union were anticipated within 9 months. Further surgical intervention was recommended to patients whose radiographs will not show progression to healing by 9 months after exchange reamed IM nailing.

Data collection procedure: Data was collected with a pre-tested structured questionnaire containing history, clinical, laboratory investigations, peri operative and follow up findings in a formulated sheet. Data sheet was formulated to evaluate the final outcome according to modified Thoresen's scoring system [4, 14]; modified Silvia`s scoring system [53] and Short-Form Musculoskeletal Function

\section{Assessment Survey SF-MFAS [54]}

To test of hypothesis pre procedure/ post procedure design was formulated in final functional outcome assessment according to SF-MFAS.

Data collection sheet: Data collection sheet is included later on.

Variables:

A. Demographic variables

Age

Sex

B. Base line variables

Side and Type of injury

Fracture Configuration Winquist Type

Type of previous fixation

Non Union Period

Status of Previous Implant

Non Union Type

C. Mechanical variables

Exchange Nail

Nail Dynamization

D. Biological Variables

Smoking

NSAIDS

Percutaneous Bone Graft or BMP

E. Outcome Variables:

Complications

Achievements

Fracture Healing 
Union time.

Final outcome

Modified Thoresen's score

Modified Silvia's score

SF-MFAS: (Short-Form Musculoskeletal Function Assessment Survey)

Analytic frame work: Data was processed and analyzed using computer software program SPSS version 19. The data present on categorical scale was expressed as frequency and corresponding percentage, while the quantitative data was presented as mean and standard deviation (SD). Comparison between preoperative and postoperative data was done using
Wilcox on Signed Rank test. Post-operative final outcome was evaluated using Z- proportion test, chisquare test, confidence interval. For all analyses level of significance was set at 0.05 and p-value $<0.05$ was considered as significant.

Ethical issue: Informed written consent was taken from the patient duly informing the procedure of treatment anticipated result, possible advantages, and disadvantage and complications considering all ethical issues according to protocol was duly passed by Ethical Committee, PMC. Confidentiality was maintained both verbally and documentary by using separate locker and computer password.

Table-2: Modified Thoresen`s Score $[4,14]$

\begin{tabular}{|l|l|l|l|l|}
\hline Criteria & Result & \multicolumn{4}{l|}{} \\
\hline & Excellent & Good & Fair & Poor \\
\hline Malalignment of femur (degrees) & \multicolumn{5}{l|}{} \\
\hline Varus/Valgus & 5 & 5 & 10 & $>10$ \\
\hline Antecurvatum/Recurvatum & 5 & 10 & 15 & $>15$ \\
\hline Internal rotation & 5 & 10 & 15 & $>15$ \\
\hline External rotation & 10 & 15 & 20 & $>20$ \\
\hline Shortening of femur (cm) & 1 & 2 & 3 & $>3$ \\
\hline Knee motion (degree) & \multicolumn{5}{|l|}{} \\
\hline Extension deficit & 5 & 10 & 15 & $>15$ \\
\hline Flexion & $>120$ & 120 & 90 & $<90$ \\
\hline Pain / swelling & None & Minor & Significant & severe \\
\hline Nonunion/Nail breakage & Absent & Absent & Absent & present \\
\hline
\end{tabular}

\section{ObServations And Results}

From July 2015 to June 2017, more than 30 patients of femoral shaft aseptic non-union could be recorded which were treated by exchange nailing with autogenous bone graft technique at $\mathrm{PMCH}$, and clinics at Pabna. 21 patients were finally recorded for study. Among them 1(one) patient was lost after 14 weeks before fracture healing. Culture of the $1^{\text {st }}$ reaming materials revealed growth in 2 cases. So, final outcome, analysis and test of significance were done with 18 patients. At least 1 year follow up was targeted to evaluate final functional outcome where union were anticipated within 9 months. But in this study total follow-up period was $38.60 \pm 5.951$ weeks. Postoperative SF-MFAS Function Index and Postoperative SF-MFAS Bother Index were taken according to last follow-up assessment.

\section{Observations}

Demographic variables, Age -Sex distribution

Table-3: Age Group and Sex Cross tabulation $(n=21)$

\begin{tabular}{|c|c|c|c|}
\hline Age Group & \multicolumn{2}{|c|}{ Sex } & Total \\
\hline & Male & Female & \\
\hline $21-30$ & 4 & 1 & 5 \\
\hline & $19.0 \%$ & $4.8 \%$ & $23.8 \%$ \\
\hline $31-40$ & 4 & 0 & 4 \\
\hline & $19.0 \%$ & $.0 \%$ & $19.0 \%$ \\
\hline $41-50$ & 4 & 2 & 6 \\
\hline & $19.0 \%$ & $9.5 \%$ & $28.6 \%$ \\
\hline $51-60$ & 4 & 2 & 6 \\
\hline & $19.0 \%$ & $9.5 \%$ & $28.6 \%$ \\
\hline Total & 16 & 5 & 21 \\
\hline & $76.2 \%$ & $23.8 \%$ & $100.0 \%$ \\
\hline
\end{tabular}

Mean age 41.95 Years; SD \pm 13.11; Male: Female $=3.3: 1$ 
15 (71.4\%) patients were within 21-50 years; which are most active ages in our society. Another $6(28.6 \%)$ were within 51-60 years. Male patients were more (16 patients-76.2\%) than female patients (5 patients-23.8\%); as male are habituated with taking more physical load [Table-3].

Base line Variables Side involvement -Type of injury

Table-4: Side involvement and Type of injury $(n=21)$

\begin{tabular}{|c|c|c|c|c|}
\hline \multirow[t]{2}{*}{ Side } & \multirow[t]{2}{*}{ involvement } & \multicolumn{2}{|c|}{ Type of injury } & \multirow[t]{2}{*}{ Total } \\
\hline & & Open & Close & \\
\hline & Right & 3 & 9 & 12 \\
\hline & & $14.3 \%$ & $42.9 \%$ & $57.1 \%$ \\
\hline & Left & 0 & 9 & 9 \\
\hline & & $.0 \%$ & $42.9 \%$ & $42.9 \%$ \\
\hline \multirow[t]{2}{*}{ Total } & & 3 & 18 & 21 \\
\hline & & $14.3 \%$ & $85.7 \%$ & $100.0 \%$ \\
\hline
\end{tabular}

Among 21 patients femoral fracture involved at right side in 12 patients $(57.1 \%)$, involved at left side in 9 patients $(42.9 \%) .18$ fractures $(85.7 \%)$ were close and 3 fractures $(14.3 \%)$ were open [Table-4].

\section{Fracture Configuration Winquist Type}

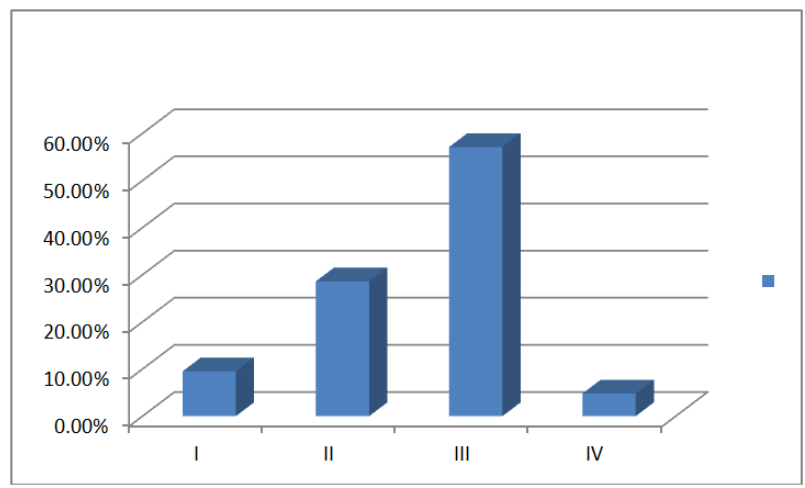

Fig-2: Bar diagram showing fracture Configuration Winquist Type $(n=21)$

Initial fracture configuration was mostly Winquist Type III (in12 patients- 57.1\%), then Type II in $28.6 \%$ ( 6 patients) and Type I in $9.5 \%$ ( 2 patients). Only one patient $(4.8 \%)$ had Type IV fracture [Figure2].

\section{Type of previous fixation}

\section{Non Union Period}

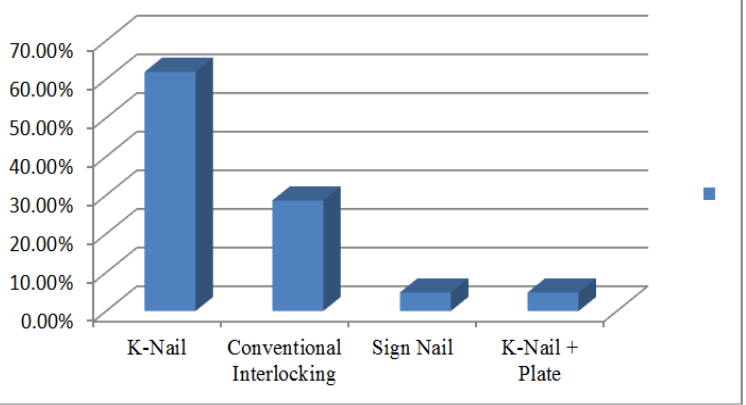

Fig-3: Area graph showing type of previous fixation $(n=21)$
Among 21 fracture Shaft Femur, 13 fractures $(61.9 \%)$ were previously fixed by K-Nail. Another 6 fractures $(28.6 \%)$ were previously fixed by conventional Interlocking Nail. Sign Nail and K-Nail + Plate were used in 1 fracture $(4.8 \%)$ separately [Figure3].

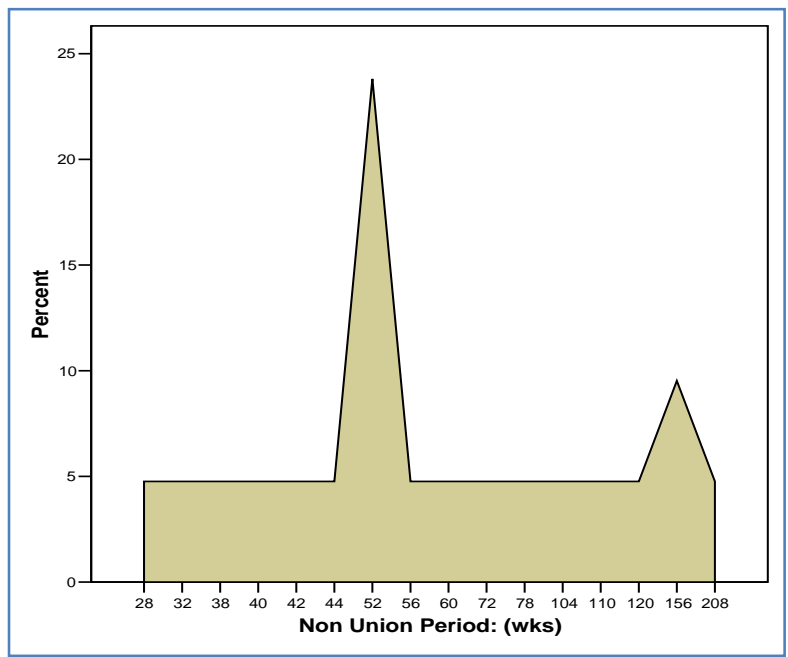

Fig-4: Area graph showing frequency of non union period $(n=21)$

Mean nonunion period was $76.38 \pm 48.38$ weeks, where 5 patients $(23.8 \%)$ were around $44-56$ weeks and 2 patients (9.5\%) were120-208 weeks delayed [Figure-4]. 


\section{Status of Previous Implant}

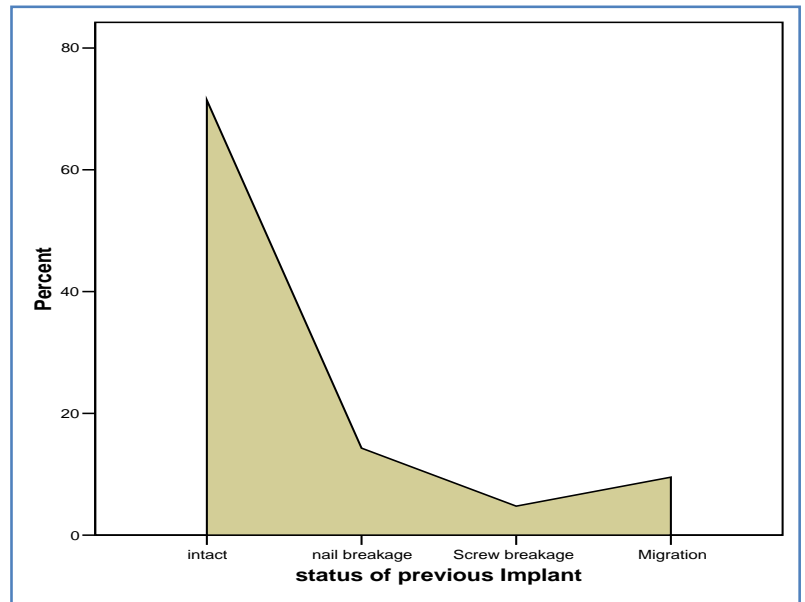

Fig-5: Area Graph showing status of previous Implant $(n=21)$

Among 21 cases, $14(71.5 \%)$ previous implant were intact. While $3(14.3 \%)$ implant were Nail breakage, $2(9.5 \%)$ implant were migrated and 1 (4.8 $\%)$ implant was screw breakage [Figure-5].

\section{Non Union Type}

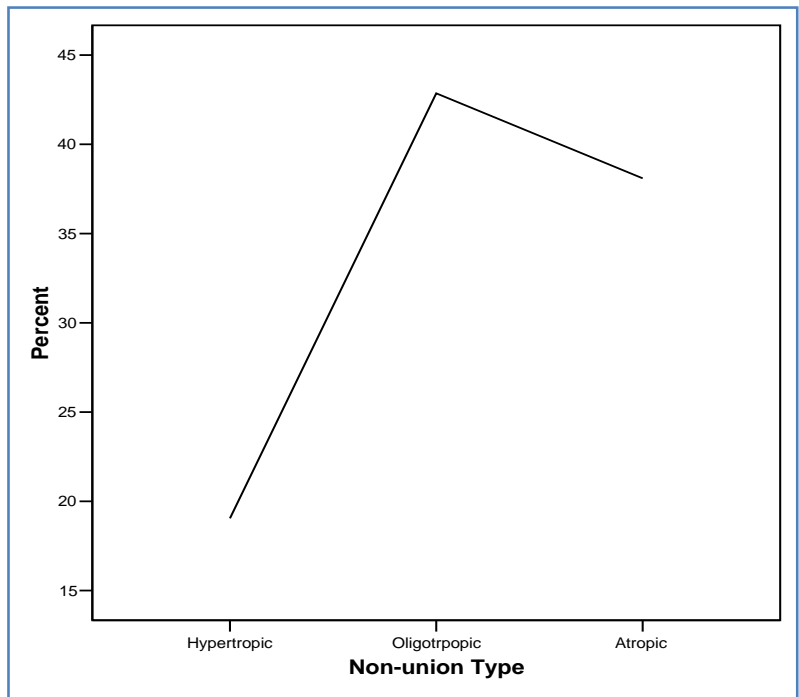

Fig-6: Line Graph showing Non union type among the study population $(\mathbf{n}=\mathbf{2 1})$

Among 21 cases, non-union type of 4 (19\%) were Hypertrophic, 9 (42.9\%) cases were Oligotrophic and $8(38.1 \%)$ cases were Atrophic [Figure-6].

\section{Mechanical variables Exchange Nail}

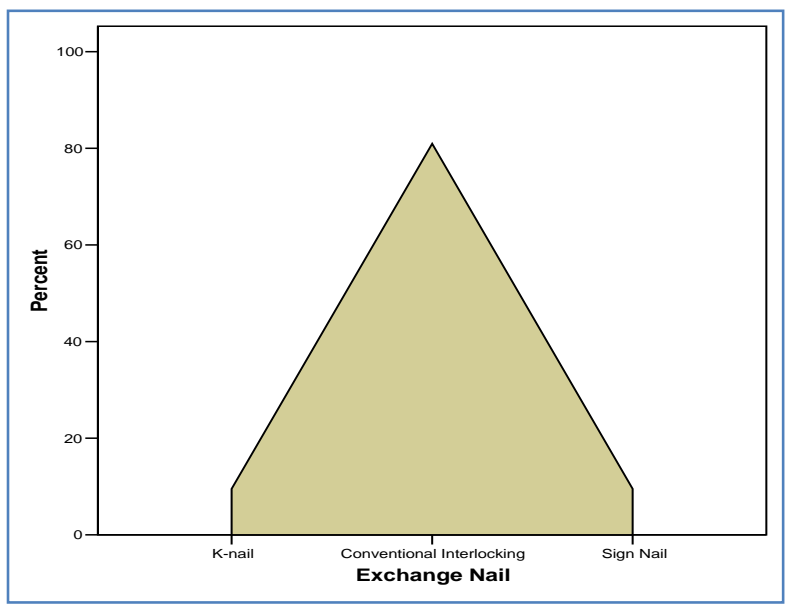

Fig-7: Area graph Type of nail used in Exchange Nail $(n=21)$

Among 21 cases, 17 (80.95\%) Exchanged nail were Conventional interlocking, while $2(9.52 \%)$ were Sign Nail and remaining $2(9.52 \%)$ case were K-Nail [Figure-7].

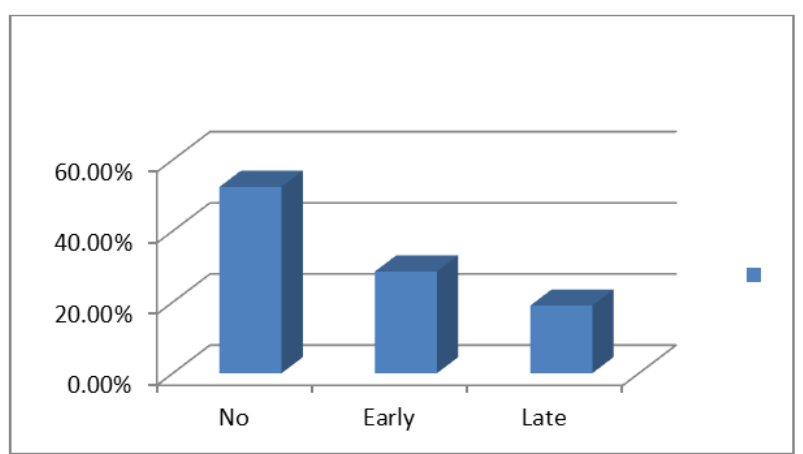

Fig-8: Bar diagram showing frequency of Nail Dynamization $(\mathbf{n}=\mathbf{2 1})$

Out of 21 patients in 11 patients $(52.4 \%)$ dynamization did not required. Among another 10 patients early dynamization was done in 6 patients $(28.6 \%)$ and late dynamization was done in 4 patients (19\%) [Figure-8].

\section{Biological Variables}

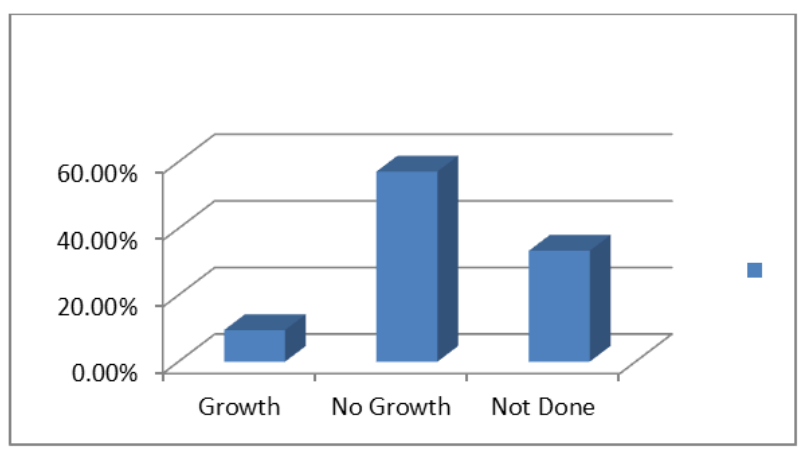

Fig-9: Bar diagram showing culture of $1^{\text {st }}$ reaming material $(\mathbf{n}=\mathbf{2 1})$ 
Culture of the 1 st reaming materials

Among 21 cases, culture of the $1^{\text {st }}$ reaming materials were done in 14 cases $(66.7 \%)$ and not done in 7 cases $(33.3 \%)$.bGrowths was found in 2 cases $(9.5$ $\%)$ which were Staph. epidermidis where Amoxiclave was sensitive. In 12 cases $(57.1 \%)$ growth were not found [Figure-9].

\section{Smoking}



Fig-10: Pie chart distribution of smoking. $(n=18)$

Among 18 Patients, 8 (44.44\%) Patients were smoked after exchange nailing [Figure-10].

\section{NSAIDS}

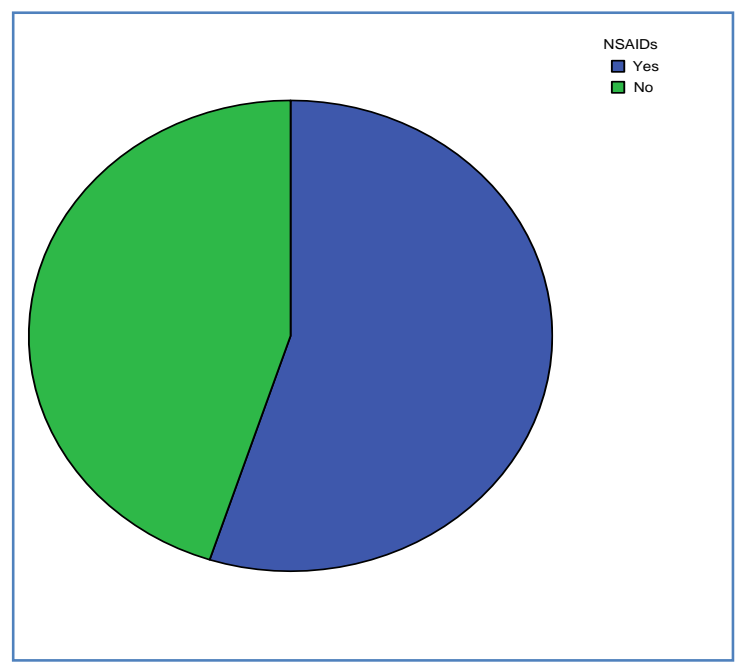

Fig-11: Pie chart distribution of NSAIDS >4weeks. $(n=18)$
Among 18 Patients, 8 (44.44\%) Patients did not required NSAIDS $>4$ weeks [Figure-11]

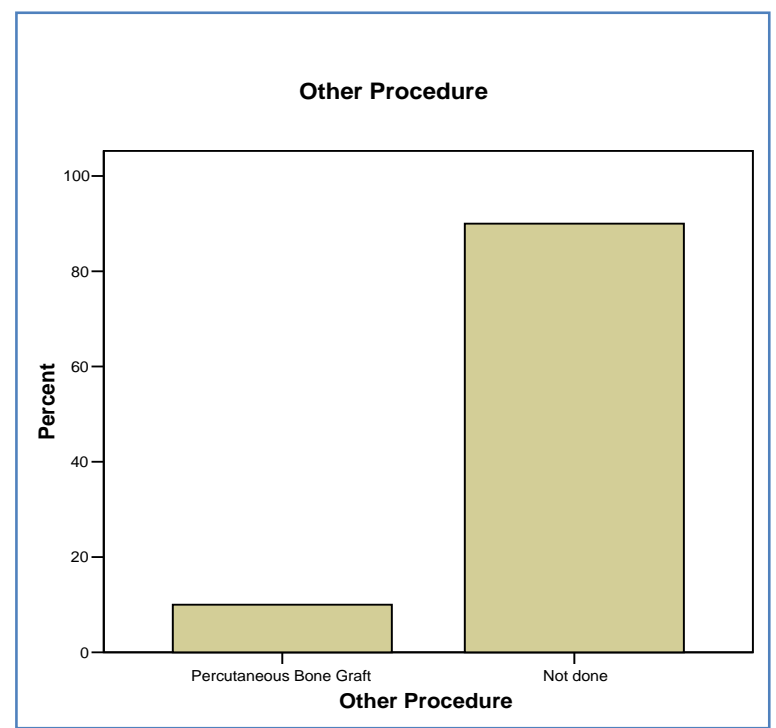

Fig-12: Bar diagram showing distribution of other procedures $(\mathbf{n}=\mathbf{2 0})$

Among 20 Patients, Percutaneous Bone Graft was done in case $2(10 \%)$ patients [Figure-12].

\section{Outcome Variables Achievements:}

Fracture Healing

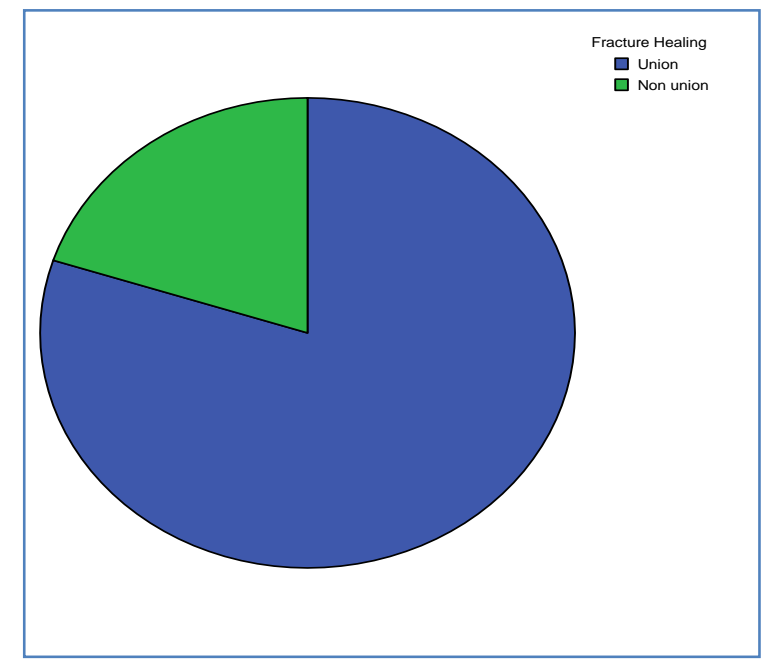

Fig-13: Pie chart showing distribution of fracture healing $(\mathrm{n}=18)$.

Among 18 fractures, 15 fractures $(83.33 \%)$ was united and 3 fractures $(16.67 \%)$ were not united [Figure-13].

\section{Union Time}

Table-5: showing union time after exchange nailing $(n=18)$

\begin{tabular}{|l|l|l|l|l|l|l|}
\hline & $\mathrm{N}$ & Mean & SD & SE & \multicolumn{2}{|l|}{ 95\% Confidence Interval of the Difference } \\
\hline & & & & & lower & Upper \\
\hline Union time (weeks) & $\mathbf{1 6}$ & $\mathbf{2 6 . 0 0}$ & $\mathbf{4 . 5}$ & $\mathbf{1 . 0 9 5}$ & $\mathbf{2 3 . 4 9}$ & $\mathbf{2 8 . 5 1}$ \\
\hline
\end{tabular}

Mean union time was $26.00 \pm 4.5$ weeks; Where $95 \%$ confidence interval was $23.49-28.51$ weeks [Table-5]. 


\section{Complications according to categories}

Table-6: Categories of Complications with frequency distribution $(n=18)$

\begin{tabular}{|c|c|c|c|c|}
\hline \multicolumn{3}{|c|}{ Complication } & \multirow[t]{2}{*}{ Frequency } & \multirow[t]{2}{*}{ Percentage \% } \\
\hline & & $<5^{\circ}$ & & \\
\hline & & $5^{\circ}-10^{\circ}$ & \multirow[t]{2}{*}{1} & \multirow[t]{2}{*}{5.6} \\
\hline & Unacceptable & $>10^{\circ}$ & & \\
\hline \multirow[t]{3}{*}{ Limb length discrepancy } & \multirow[t]{2}{*}{ Acceptable } & Lower limbs equalization & \multirow[t]{2}{*}{17} & \multirow[t]{2}{*}{94.4} \\
\hline & & Shortening existing as previous & & \\
\hline & Unacceptable & Shortening > previous surgery & 1 & 5.6 \\
\hline \multirow[t]{4}{*}{ Pain and swelling } & \multirow[t]{2}{*}{ Acceptable } & No & \multirow[t]{2}{*}{17} & \multirow[t]{2}{*}{94.4} \\
\hline & & Minor & & \\
\hline & \multirow[t]{2}{*}{ Unacceptable } & Significant & \multirow[t]{2}{*}{1} & \multirow[t]{2}{*}{5.6} \\
\hline & & Severe & & \\
\hline \multirow[t]{3}{*}{ Infection } & Acceptable & No & 16 & 88.88 \\
\hline & \multirow[t]{2}{*}{ Unacceptable } & Wound infection & \multirow[t]{2}{*}{2} & \multirow[t]{2}{*}{11.12} \\
\hline & & Bone infection & & \\
\hline \multirow[t]{3}{*}{ Joint Motion } & \multirow[t]{2}{*}{ Acceptable } & Normal & \multirow[t]{2}{*}{17} & \multirow[t]{2}{*}{94.4} \\
\hline & & Flexion up-to $90^{\circ}$ & & \\
\hline & Unacceptable & $<90^{\circ}$ & 1 & 5.6 \\
\hline \multirow[t]{2}{*}{ Implant Failure } & Acceptable & Absent & 17 & 94.4 \\
\hline & Unacceptable & Present & 1 & 5.6 \\
\hline
\end{tabular}

\section{Final outcome Modified Thoresen's Score}

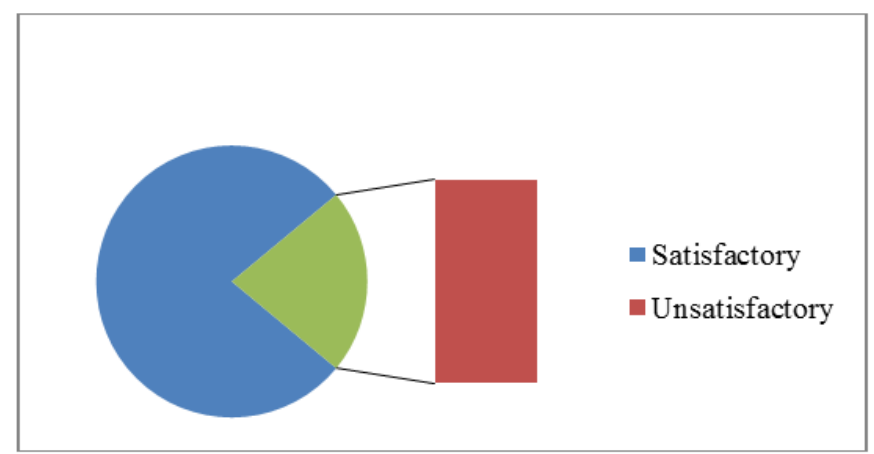

Fig-14: Pie chart showing outcome according to modified Thoresen's score

Satisfactory= Excellent $(28 \%)+$ Good $(50 \%)=78 \%$ Unsatisfactory= Fair $(5.6 \%)+$ Poor $(16.4 \%)=22 \% 95 \%$ Confidence Interval of satisfactory outcome $=58.87 \%-97.13 \%$ [Figure-14].

\section{Modified Silvia's score}

Table-7: Showing final outcome according to Silvia's score $(n=18)$

\begin{tabular}{|l|l|l|l|l|l|l|}
\hline & $\mathbf{N}$ & Mean & SD & SE & 95\% Confidence Interval of the Difference \\
\hline & & & & & Upper & Lower \\
\hline Silvia's Score & 18 & 10.83 & 2.23 & 0.488 & 9.74 & 11.93 \\
\hline
\end{tabular}

According to modified Silvia's score, final outcome of exchange nailing in this study was $10.83 \pm$ 2.203 where $95 \%$ Confidence interval was 9.74-11.93.
Lowest out come at 95\% Confidence interval was 9.74; that is almost 10. According to modified Silvia's score this outcome is graded as 'Good' [Table-7].

\section{SF-MFAS: Short-Form Musculoskeletal Function Assessment Survey}

Table-8: Pre-operative and post operative SF-MFAS $(n=18)$

\begin{tabular}{|l|l|l|l|}
\hline & Index & & Index \\
\hline Preoperative SF-MFAS Function Index & $46.62 \pm 10.96$ & Postoperative SF-MFAS Function Index & $5.17 \pm 6.95$ \\
\hline Preoperative SF-MFAS Bother Index & $37.26 \pm 12.59$ & Postoperative SF-MFAS Bother Index & $4.65 \pm 6.58$ \\
\hline
\end{tabular}


Postoperative SF-MFAS Function Index and Postoperative SF-MFAS Bother Index were taken according to last follow-up assessment among 18 patients. Function index and Bother index also were calculated within the patients whose fractures had united after exchange nailing. Function index was $2.5 \pm 1.7$ and Bother index was $1.89 \pm 1.08$. Less the index means more the functioning [Table-8].

\section{ANALYSIS}

Fracture Healing

Among 18 fractures nonunion, 15 fractures $(83.33 \%)$ were united and 3 fractures $(16.67 \%)$ were not united after exchange nailing with autogenous bone graft in aseptic condition [Table-9].

Table-9: Showing distribution of fracture healing and Statistics

\begin{tabular}{|l|c|l|l|}
\hline Fracture healing & Frequency & Percent & $\begin{array}{l}\text { Confidence Interval at 95\% } \\
\text { level(Union rate) }\end{array}$ \\
\hline Union & 15 & $\mathbf{8 3 . 3 3 \%}$ & \multirow{2}{*}{$\mathbf{6 6 . 0 8 \% - 1 0 0 \%}$} \\
\hline Nonunion & $\mathbf{0 3}$ & $\mathbf{1 6 . 6 7 \%}$ & $\mathbf{2}$ \\
\hline
\end{tabular}

So, it could be said that after exchange nailing with autogenous bone graft in femoral shaft non union;
Union rate will be minimum $66.08 \%$ as well as maximum $100 \%$.

\section{Union Time}

Table-10: showing union time after exchange nailing and Statistics

\begin{tabular}{|c|c|c|c|c|c|}
\hline Mode & $\begin{array}{c}\text { Frequency of } \\
\text { union }\end{array}$ & Mean & SD & $\begin{array}{c}\text { 95\% Confidence Interval of the } \\
\text { Difference }\end{array}$ \\
\hline & & & & Lower & Upper \\
\hline Exchange nailing & $\mathbf{1 5}$ & $\mathbf{2 6 . 0 0}$ & $\mathbf{4 . 5}$ & $\mathbf{2 3 . 4 9}$ & $\mathbf{2 8 . 5 1}$ \\
\hline Exchange nailing static & $\mathbf{6}$ & $\mathbf{2 9 . 3 3}$ & $\mathbf{3 . 0 1}$ & $\mathbf{2 6 . 1 7}$ & $\mathbf{3 2 . 4 9}$ \\
\hline $\begin{array}{c}\text { Exchange nailing early } \\
\text { dynamic }\end{array}$ & $\mathbf{6}$ & $\mathbf{2 1 . 3 3}$ & $\mathbf{1 . 6 3 3}$ & $\mathbf{1 9 . 6 2}$ & $\mathbf{2 3 . 0 5}$ \\
\hline $\begin{array}{c}\text { Exchange nailing late } \\
\text { dynamic }\end{array}$ & $\mathbf{3}$ & $\mathbf{2 8 . 6 7}$ & $\mathbf{2 . 3 0 9}$ & $\mathbf{2 2 . 9 3}$ & 34.40 \\
\hline
\end{tabular}

Mean union time was $26.00 \pm 4.5$ weeks where $95 \%$ confidence interval was 23.49-28.51 weeks including both static and dynamic mode of fixation. In static mode mean Union time was a $29.33 \pm 3.01$ week whereas in early dynamic it was $21.33 \pm 1.63$ weeks. It was also calculated that after late dynamization mean Union time was $28.67 \pm 2.309$ weeks. There were not enough cases to compute further statistics analysis [Table-10].

\section{Influence of various factors on Fracture Union and union time Age}

Table-11: Showing relation between age and Union time

\begin{tabular}{|l|r|r|r|l|}
\hline & Mean & \multicolumn{1}{|c|}{ SD } & N & Nonparametric Correlation Coefficient \\
\hline Age & 43.17 & 12.41 & 18 & 1.000 \\
\cline { 1 - 4 } Union time (weeks) & 26.00 & 4.5 & 15 & \\
\hline
\end{tabular}

It is highly strong positive correlation; that means more the age more the union time [Table-11]. 


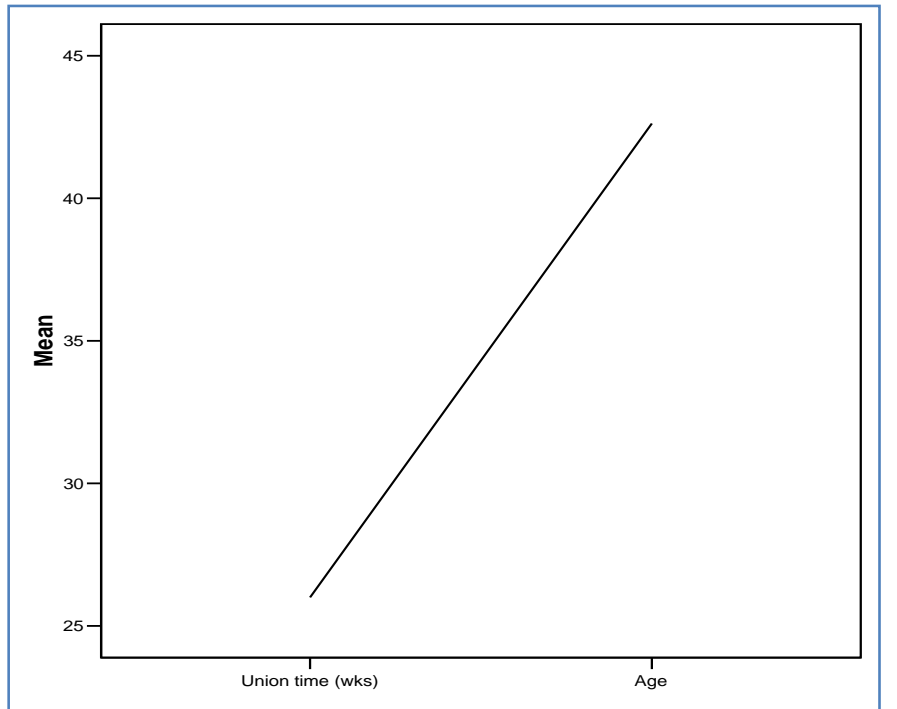

Fig-15: Line Graph showing positive correlation between Age and Union time. Smoking and NSAIDs

Table-12: Relation of smoking and NSAIDs with fracture healing

\begin{tabular}{|c|l|l|l|c|}
\hline \multirow{2}{*}{ Factors } & \multicolumn{2}{|c|}{ Fracture Healing } & Union time (weeks) \\
\cline { 2 - 5 } & Chi-Square Value (Pearson) & P -Value & Chi-Square Value (Pearson) & p-Value \\
\hline Smoking & 0.720 & $0.396(>0.05)$ & 10.00 & $0.040(<0.05)$ \\
\hline NSAIDs & 2.88 & $0.090(>0.05)$ & 12.32 & $0.015(<0.05)$ \\
\hline
\end{tabular}

In this study, it was found that smoking and NSAIDs both had significant relation $(\mathrm{p}<0.05)$ with fracture union time [Table-12].

\section{Correlations between Non-union period and Union time}

Table 13: Statistics between Non-union period and Union time

\begin{tabular}{|l|r|r|r|l|}
\hline & Mean & \multicolumn{1}{|c|}{ SD } & N & Correlation Coefficient \\
\hline Non Union Period: (weeks) & 79.00 & 51.733 & 18 & 1.000 \\
& 26.00 & 4.5 & 15 & $(+) \mathrm{ve}$ \\
\hline Union time (weeks) & & & & \\
\hline
\end{tabular}

Highly strong (+) ve correlation between nonunion period and union time after exchange nailing [Table-13]

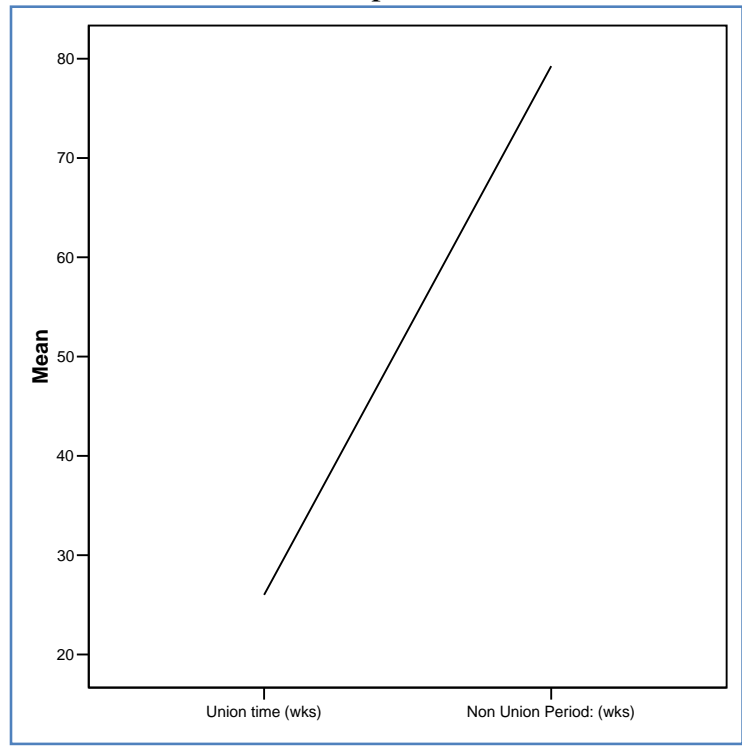

Fig-16: Line graph showing 
Correlation between union time and non-union periods. More the nonunion period more the union time was found in this series [Figure-16].

\section{Influence of Multiple random factors on Union time at a time}

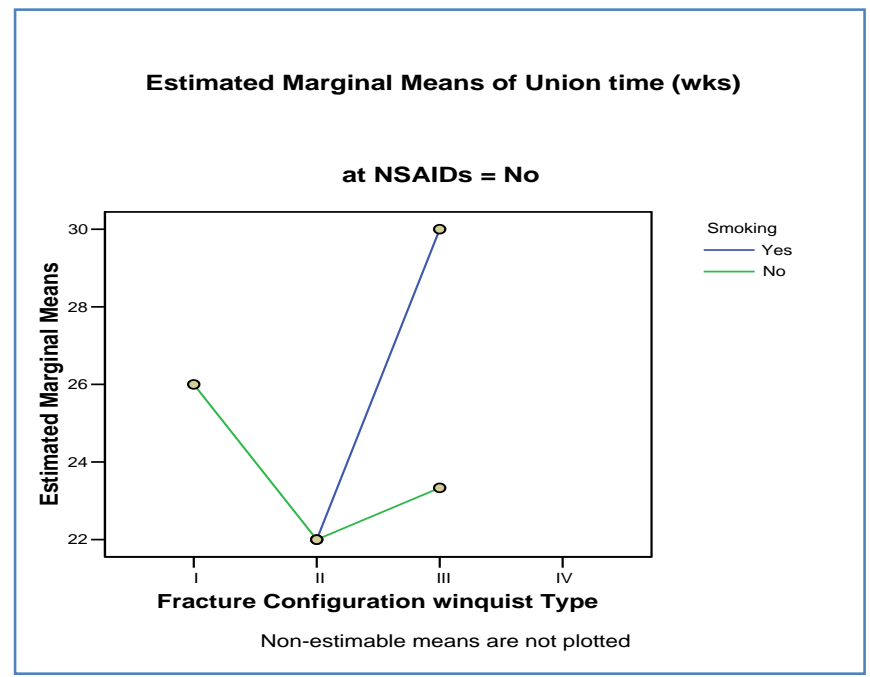

Fig-17: Profile Plots showing Influence of fracture configuration, NSAIDS and smoking

When NSAIDs were used <4weeks and smoking was absent union time was less in Winquist type I,II, III .But when smoking was present union time increased [Figure-17].

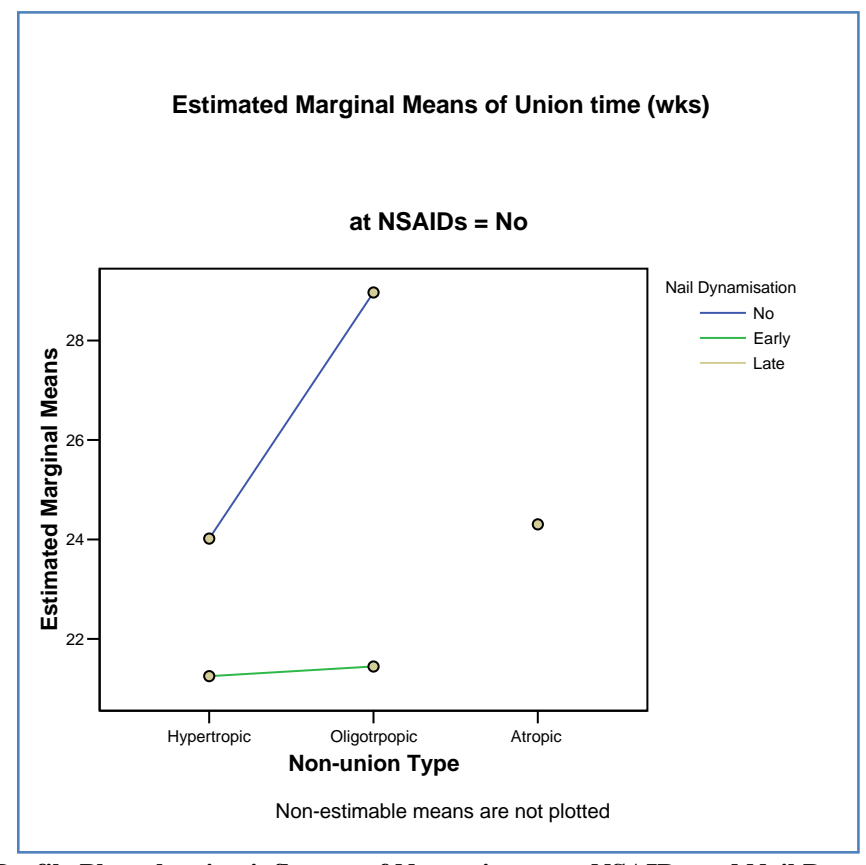

Fig-18: Profile Plots showing influence of Non union type, NSAIDs and Nail Dynamization.

When, NSAIDs were used <4weeks early Nail Dynamization reduced union time in hypertrophic and oligotrophic nonunion than no dynamization. But on atrophic non union dynamization had no influence [Figure-18].

\section{DISCUSSION}

From July 2007 to June 2008, more than 30 patients of femoral shaft aseptic nonunion were treated with this technique at $\mathrm{PMCH}$ and clinics in Pabna. 21 patients were finally recorded for study. Among them 1(one) patient was lost after 04 weeks before fracture healing. Culture of the $1^{\text {st }}$ reaming materials revealed growth in 2 cases. So, final outcome, analysis and test of significance were done with 18 patients. One basic work on exchange nailing with autogenous cancellous bone graft were done by $\mathrm{Wu}$ and Chen from January 1989 to 1993 in China with 19 patients. They compared this open method with close method (16 patients)[38]. Another basic work done by Furlong et al. on 1999 in UK with 22 patients where open bone grafting was done 
in12 patients [37]. On 2006-2007, Dr.Sharkar KM did a study on exchange nailing for femoral shaft nonunion by SIGN nail in NITOR, Dhaka. Number of cases was 28[67]. Naturally 5-10\% nonunion may occur in any long bone fracture; [74] from this prevalence any study on femoral nonunion should include at least 100 patients. Due to various constraints this large sample experimental study was not done. Some retrospective studies on hospital records were done but most of them were again with less sample and inconsistent with this procedure; which is more commonly done in developed country. In this study exchange nailing with autogenous cancellous bone graft were done for femoral shaft nonunion in 21 patients. Among them 15 (71.4\%) patients were within 21-50 years; which are most active ages in our society. Another 6(28.6\%) were within 5160 years. Male patients were more (16 patients-76.2\%) than female patients (5 patients-23.8\%); as male are habituated with taking more physical load. Mean age was 41.95years; SD \pm 13.11; Male: Female 3.3:1. Here, a highly strong correlation was found between age and union time .More the age more the union time. In the series of $\mathrm{Wu}$ and Chen median age was 34 years and male: female was 7:1. In Sharker's series, mean age was 40.77 years and male female ratio was 3:2. In present series among 21 patients most were heavy or moderate worker $(76 \%)$; other was sedentary worker. Almost all fractures initially caused by motor vehicle accident. Among 21 patients femoral fracture involved at right side in 12 patients $(57.1 \%)$, involved at left side in 9 patients $(42.9 \%) .18$ fractures $(85.7 \%)$ were close and 3 fractures $(14.3 \%)$ were open. Fractures involving left side were $100 \%$ close but at right sided fractures about $75 \%$ were close and about $25 \%$ were open. Initial fracture configuration was mostly Winquist Type III (in12 patients- 57.1\%), then Type II in 28.6\% (6 patients) and Type I in 9.5\%(2 patients).Only one patient $(4.8 \%)$ had Type IV fracture. Among 21 fractures 13 fractures $(61.9 \%)$ were previously fixed by K-nail, another 6 fractures $(28.6 \%)$ were previously fixed by conventional interlocking nail, SIGN nail and $\mathrm{K}$-nail plate were used in one fracture of remaining two fractures. Among 21 cases, culture of the $1^{\text {st }}$ riming materials were done in 14 cases $(66.7 \%)$ and not done in 7 cases $(33.3 \%)$. Growths was found in 2 cases $(9.5$ $\%$ ) which were Staph. epidermidis where Amoxiclave was sensitive and in 12 cases $(57.1 \%)$ growth were not found. In growth $(+)$ ve cases antibiotics were given as full dose for 6 weeks then continued as suppressive dose up to union anticipated. One fracture healed within 26 weeks but another fracture not healed and clinically no infection. Mean nonunion period was $76.38 \pm 48.38$ weeks, where 5 patients $(23.8 \%)$ were around $44-56$ weeks and 2 patients (9.5\%) were120-208 weeks delayed. In the series of $\mathrm{Wu}$ and Chen, some patients under gone as many as four operations, and the nonunion periods were as long as 4 years. In the series one patient had under gone third operations [38]. In the series, highly strong (+) ve correlation between nonunion period and union time after exchange nailing was found. Among 21 cases, 14 (71.5\%) previous implant were intact. While $3(14.3 \%)$ implant were Nail breakage, $2(9.5 \%)$ implant were migrated and 1 (4.8\%) implant was screw breakage. Among 21 cases, nonunion type of $4(19 \%)$ were Hypertrophic, 9 $(42.9 \%)$ cases were Oligotrophic and $8(38.1 \%)$ cases were Atrophic. Among 21 cases, 17 (80.95\%) exchanged nail were Conventional interlocking, while 2 $(9.52 \%)$ were Sign Nail and remaining $2(9.52 \%)$ case were K-Nail. Out of 21 patients in 11 patients $(52.4 \%)$ dynamization did not required. Among another 10 patients early dynamization was done in 6 patients $(28.6 \%)$ and late dynamization done in 4 patients (19\%). Mean union time was $26.00 \pm 4.5$ weeks where $95 \%$ confidence interval was 23.49-28.51weeks including both static and dynamic mode of fixation. In static mode mean Union time were $29.33 \pm 3.01$ weeks whereas in early dynamic it was $21.33 \pm 1.63$ weeks. It was also calculated that after late dynamization mean Union time was $28.67 \pm 2.309$ weeks. Court -Brown et al have stated that locking screws are often unnecessary in exchange nailing. These authors have proposed that locking of the exchange nail is necessary only when there is instability of the construct or a peri articular nonunion with a small distal or proximal fragments[50]. $\mathrm{Wu} \mathrm{CC}$, Chen $\mathrm{W} \mathrm{J}$, have found no difference in the healing rates or time to union between patients treated with a statically locked nail and those treated with a dynamically locked nail. [38] Hak DJ stated that gradual axial compression at the non union site can be attain with a statically locked exchange nail if it has slotted interlocking holes[17] In this study, it was found that smoking and NSAIDs both had significant relation $(\mathrm{p}<0.05)$ with fracture union time. Oleksak et al. 2002 statistically shows that there is no significant difference between smokers and nonsmokers in relation to fracture healing but an increased time to union in the heavy smoker group $(>40$ cigarettes per day)[42]. Hak DJ. Lee SS, Goulet JA. on 2000 reported their investigation on success of exchange reamed femoral nailing in the treatment of femoral non-union after intramedullary nailing and analysis on factors those may contribute to failure of exchange reamed femoral nailing[17]. They work on 23 patients; all were treated by exchange reamed femoral nailing for their femoral shaft nonunion or delayed union. Eighteen patients out of twenty three healed without additional procedure $(78.3 \%)$. Of the five patients whose fractures failed to unite after exchange nailing, all were smokers and all had atrophic non-unions. They reported that in their series all of the eight non-smokers healed after exchange reamed nailing. Only ten of the fifteen smokers (66.7\%) achieved union after exchange reamed nailing (95\% confidence interval, 43.1 to $90.9 \%$ ). P.V.Giannoudis, D.A.MacDonald et al. reported a marked association between non-union and the use of NSAIDS after injury $(\mathrm{P}=0.000001)$ and delayed healing was noted in patients who took NSAIDS and whose fractures had united [37]. Daftari TK stated that nicotine has a detrimental affect on fracture nonunion as it delay and 
decrease revascularization of the associated bone graft [75]. Among complications unacceptable Angle deviation 5.6\%, Limb length discrepancy 5.6\%, Pain Swelling $5.6 \%$, Infection $11.12 \%$, Joint motion restriction $5.6 \%$, Implant failure $5.6 \%$. In the series of $\mathrm{Wu}$ and Chen the knee range of motion in all cases did not deteriorate compared with the preoperative status. Furthermore, some cases even improved somewhat after fracture healing. There were no wound infection, leg length discrepancies $(>2 \mathrm{~cm})$, or rotational or angular deformities ( $>15$ degrees) noted. The operating time with the closed technique was $36+/-7$ minutes and with the open technique 58+/-14 minutes $(\mathrm{p}<0.01)$ [38]. In the series of $\mathrm{Wu}$ and Chen all 19 patients of non union treated by open method where union time was $5.1 \pm 0.8$ months. Where as in closed method union rate was $100 \%$ but union period was $4.0 \pm 0.6$ months. They concluded that closed bone grafting should be use to treat aseptic nonunion if possible. Otherwise open technique could be used as second choice. ${ }^{38}$ In the series of Furlong et al. [21] patients out of 22 had osseous union after exchange nailing, all 12 patients in whom autogenous bone graft has been placed at the non union site at the time of the nail exchange had osseous union after procedure. Average time to union was 7 months. ${ }^{37}$ Among 18 fractures nonunion, 15 fractures $(83.33 \%)$ were united and 3 fractures $(16.67 \%)$ were not united after exchange nailing with autogenous cancellous bone graft in aseptic condition. Confidence Interval at $95 \%$ level $66.08 \%-100 \%$. Mean union time was $26.00 \pm 4.5$ weeks where $95 \%$ confidence interval was $23.49 \pm 28.51$ weeks including both static and dynamic mode of fixation. Final outcome according to modified Thoresen's score Satisfactory78 \%; ( Excellent28\%+ Good50\%) Unsatisfactory 22\% (Fair5.6\%+ Poor $16.4 \%)$. In Sharkar`s study, rate of fracture healing was around $80 \%$, average union period was 28.09 weeks. Final outcome was $60.71 \%$ excellent, $21.43 \%$ good,10.72\%fair, $7.14 \%$ poor according to Thoresen`s score[67]. Though there are so many controversy about SIGN nail (Tibial nail) used in femur; results of current study almost compatible to Sharkar`s study. According to modified Silvia's score, final outcome of exchange nailing in this study was $10.83 \pm 2.203$ where $95 \%$ Confidence interval was $9.74-11.93$. So, it is $95 \%$ sure that among whole population of femoral nonunion treated by exchange nailing with extra cortical bone graft minimum Silvia`s score will be about 10; a 'Good outcome. So, initial fracture fixation should be accurate as much as possible. Two recent reports have question the effectiveness of exchange nailing in the treatment of non-union following intramedullary nailing of comminuted fracture of the femoral diaphysis. Weresh et al. reported that only ten of nineteen femoral diaphyseal non-unions following locked intramedullary nailing of comminuted fractures of the femoral diaphysis went onto osseous union after treatment with exchange nailing [18] Similarly Banaszkiewicz et al. reported that only eleven of nineteen aseptic femoral non-unions following locked intramedullary nailing of high energy, comminuted fractures went onto osseous union after treatment with exchange nailing alone. The authors of both papers stated that since the introduction of interlocking screws and other technological advances intramedullary nailing is used to treat more complex femoral fractures are more likely to go onto non-union and that this non-union may not be appropriate for exchange nailing [65-74]. Pihlajamaki et al. reported that fourteen of eighteen patients with an aseptic midshaft femoral non-union had osseous union after a single exchange nailing procedure; all three patients in whom an autogenous bone graft had been placed had osseous union after a single procedure [51]. In contrast, Weresh et al. found that osseous union fail to occur in three of four patients who had undergone open bone grafting at the time of an exchange nailing [18]. In this study total follow-up period was $38.60 \pm 5.951$ weeks. Postoperative SF-MFAS Function Index and Postoperative SF-MFAS Bother Index were taken according to last follow-up assessment. Function index and Bother index also were calculated within the patients whose fractures had united after exchange nailing. Function index was $2.5 \pm 1.7$ and Bother index was $1.9 \pm 1.08$. Less the index means more the functioning. WuCC, Chen W J stated that, femoral shaft nonunion are often combined with extension contracture of the ipsilateral knee, which are usually caused by quadriceps adhesion. Because releasing the contracture usually requires extensive soft tissue dissection and forceful manipulation, it can produce additional severe vascular destruction, which has higher infection rate and impedes the fracture healing process. This procedure, therefore, should be postponed until the nonunion site has healed, active and aggressive exercises of knee may improve the knee range of motion. Thus, later some cases may be unnecessary or minimized with the dissection to improve the knee function [38].

\section{Conclusion}

Exchange nailing with autogenous cancellous bone graft seems to be an effective method of treatment in femoral shaft nonunion after intramedullary nailing. It provides a good scope to reinforce the optimum mechanical stability by a larger diameter nail and locked if necessary; as well as biological stimulation by reaming and open bone grafting. Though union time is longer (mean union time $26 \pm 4.5$ weeks), union rate $(83.33 \%)$ is very much comparable. Functional outcome is also substantial. Effects of smoking, NSAIDs and prolonged nonunion period on healing should be reevaluated.

\section{LIMITATIONS AND RECOMMENDATIONS Limitations}

Due to financial constraint following operation, majority of the patients were reluctant to 
follow up visit and that was increased more after $3^{\text {rd }}$ visit (at the end of $10^{\text {th }}$ weeks) when advised for $50 \%$ to one crutch assisted weight bearing. Due to time constraint required sample could not be collected.

\section{Recommendations}

To achieve success in exchange nailing with autogenous cancellous bone graft for aseptic nonunion of femoral shaft following measures should be emphasized:

1. Realignment, optimum stable fixation and nail selection should be standard as per requirement.

2. Less soft tissue handling and enough bone grafting.

3. $1^{\text {st }}$ reamed materials should be sent for culture and sensitivity. If (+)ve, sensitive antibiotics as a full dose for 6 weeks then continue as suppressive dose up to fracture healing.

4. Early mobilization, weight bearing according to fracture configuration.

5. Dynamization enhance healing but it is not suitable and essential in all cases.

6. Due to inherent potentiality to non-union; after exchange nailing union period could be prolonged.

7. Post-operative avoidance of smoking and less use of NSAIDs may accelerate healing.

\section{REFERENCES}

1. Lynch JR, Taitsman LA, Barei DP, Nork SE. Femoral nonunion: risk factors and treatment options. JAAOS-Journal of the American Academy of Orthopaedic Surgeons. 2008 Feb 1;16(2):88-97.

2. Adam JC, Stossel CA. Standard Orthopaedic Operations. $1^{\text {st }}$ ed, Edinburgh: Churchill livingstone.1976: 253-256.

3. Kempf I, Grosse A, Beck G. Closed locked intramedullary nailing: its application to comminuted fractures of the femur. J Bone Joint Surg Am. 1985; 67:709-715

4. Thorensen BO. Interlocking intramedullary nailing in femoral shaft fractures: A report of forty-eight cases. J Bone Joint Surgery. 1985; 67:1313-1331.

5. White GM, Healy WL, Brumbeck RJ. The treatment of fractures of femoral shaft with the Brooker-Wills distal locking intramedullary nail.J bone Joint Surg.1986; 68A:865-867.

6. Taylor JC. Treatment of distal femoral fractures with the Russell-Taylor nail. Tech Orthop. 1994;9:225-228.

7. A. Canale ST, Daugherty K, Jones 1, editors. Campbell's operative Orthopaedics. $10^{\text {th }}$ edition,St.Louis:Mosby. 2003(3): 2827-2839

8. B. Canale ST, Daugherty K, Jones 1,editors. Campbell's operative Orthopaedics. $10^{\text {th }}$ edition,St.Louis:Mosby. 2003. 3: 3125-3150

9. Rfiedi TP, Luscher JN. Results after internal fixation of comminuted fractures of the femoral shaft with DC plates. Clin Orthop. 1979;138:74-77

10. Winquist RA, Hansen ST Jr. Comminuted fractures of the femoral shaft treated by intramedullary nailing. Orthop Clin North Am. 1989;11:631-634
11. Schatzker J. Fractures of the femur:The rationale of Operative Fracture care. Springer. 1996;3:367-385.

12. Richard RT, Donald AW. The Mechanics and biology of Intramedullary Fracture Fixation. Clinical Orthopaedics and Related Research. 1986;212:10-17

13. Tanna DD . Interlocking Nailing. New Delhi: Jaypee; 2001

14. OlasindeAA. Open Kuntscher Nailing of Closed Femoral Shaft Fractures: Revisited. The Internet Journal of Third World Medicine.2006; 3(2)

15. Basumallick MN, Bandopadhyay A. Effect of dynamization in open interlocking nailing of femoral fractures: A prosfective randomized comparative study of 50 cases with a 2-years follow-up. Acta Orthopaedica Belgica. 2002 ;68$1: 42-48$

16. Grantham SA, Craig M. Open intramedullary nailing of the femoral shaft fracture. Orthop Rev. 1986; 15:426-431

17. $\mathrm{CK} \mathrm{Yu,} \mathrm{Wong} \mathrm{HY,} \mathrm{VIvek} \mathrm{AS.Unlocked} \mathrm{Nailing}$ vs. Interlocking Nailing for Winquist Type I and II Femoral Isthmus Fractures. Is there a Difference ? Malaysian Orthopaedic Journal. 2008; 2(1):23-27

18. Hak DJ, Lee SS, Goulet JA. Success of exchange reamed intra medullary nailing for femoral shaft nonunion or delayed union. J Orthop trauma. 2000; 14:178-182

19. Weresh MJ, Hakason R. Failure of exchange reamed intramedullary nails for un united femoral shaft fractures. J OrthopTrauma. 2000; 14:335-338

20. Wu CC, Shih CH. Effect of dynamization of a static interlocking nail on fracture healing. Can J Surg. 1993;36:302-306

21. Canadian Orthopaedic Trauma Society. Nonunion following intramedullary nailing of the femur with and without reaming: Results of a multicenter randomized clinical trail. J Bone Joint Surg (Am). 2003 Nov;85-A (11):2093-96.

22. Winquist RA,Hansen Jr, Clawson DK. Closed intramedullary nailing of femoral fractures: A report of five hundred and twenty cases. J Bone Joint Surg (Am). 1984;66:529-539.

23. Wolinsky PR, Mc Carty E,Shyr Y,Johnson K. Reamed intramedullary nailing of the femur:551 cases. J Trauma. 1999;46:392-399

24. Webb LX, Winquist RA, Hansen ST. Intramedullary nailing and reaming for delayed union or nonunion of the femoral shaft:a report of 105 consecutive cases. Clin Orthop. 1986; 212:133116

25. Cove JA, Lhowe DW, Jupiter JB, Siliski JM. The management of femoral diaphyseal nonunions. J Orthop Trauma. 1997;11:513-520

26. Einhorn TA.Clinical applications of recombinant human BMPs: Early experience and future development .J Bone Joint Surg (AM). 2003;85(suppl 3):82-88

27. Friendlaender GE, Perry CR, Cole JD. Osteogenic protein-1(bone morphogenetic protein-7) in the 
treatment of tibial non unions.J Bone Joint Surg( Am). 2001;83 (suppl. 1 ):151- 158

28. Vidal J, Buscayret C, Connes H, Melka J, Orst G. Guideline for treatment of open fractures and infected pseudoarthoses by external fixation.Clin Orthop.1983;180:83-95

29. H G Jung, D J Kim, B H Kim, Y Y Chung.Treatment of the femoral shaft nonunion occurred after intramedullary nailing.J Korean Orthop Assoc. 2007;42:653-658

30. Judet PR, Patel A. Muscle pedicle bone graft of long bones by osteoperiosteal decortication.Clinical Orthop. $1972 ; 74-80$.

31. Arazi M, Ogun TC, Oktar MN. Early weightbearing after statically locked reamed intramedullary nailing of comminuted femoral fracture: Is it safe procedure? J Trauma. 2001; 50:1711-1716

32. Brumback RJ, Toal TR, Murphy Z. Immediate weight bearing after treatment of a comminuted fracture of the femoral shaft with a statically locked intramedullary nail. J Bone Joint Surg.( Am). 1999; 81:1538-1544

33. Foster TE, Healy WL. Operative management of distal femoral fractures. Orthop Rev. 1991; 20: 962-969

34. Meadows TH, Bronk JT, Chao YS, Kelly PJ. Effect of weight_bearing on healing of cortical defects in the canine tibia. J Bone Joint Surg.(Am). 1990; 72: 1074-1080

35. Einhorn TA, Enhancement of fracture-healing. J Bone Joint Surg.(Am).1995; 77: 940-956

36. Hulth A. Current Concepts of fracture healing. Clin Orthop Relat. Res. 1989 ;265-284

37. Oldman M. Fast Track Orthopaedic Surgery.South west Regional Anaesthesia group. Published on 10/02/2006. http://www.sowra.org.uk

38. Furlong AJ, Giannoudis PV, Deboer P. Exchange nailing for femoral shaft aseptic non-union. Injury. 1999; 30:245-250.

39. Wu CC, Chen WJ. Treatment of femoral shaft aseptic nonunions: comparison between closed and open bone-grafting techniques. J Trauma. 1997; 43:112-127

40. Wu CC, Shih CH. Treatment of 84 cases of femoral nonunion. Acta Orthop Scand. 1992; 63:57-61.

41. Clifford R. Wheeless. Femoral shaft nonunion.Wheeless Text Book of Orthopaedics,Last update on july. 2008 http://www.wheelessonline.com/ortho/non_union

42. Wu Oiang. Cortical Stripping Pediculated tablets for the treatment of non union. Henan surgery. 2001;04: 51-56

43. Ricardo J P, Martin DB. Review management of nonunion in trauma. Trauma. 2004;6:225-247

44. Eid AM, Deif AI. Etiological factors in nonunion following kuntscher intramedullary nailing of the femur. Arch Orthop Trauma Surg.1980;96:213-220
45. Wickstrom J, Corban M,Vise G. Complications following intramedullary fixation of 324 femoral fractures. Clin Orthop. 1968;60:103-113

46. Burchardt $\mathrm{H}$. The biology of bone graft repair.Clin Orthop. 1983;174:28-32

47. Gross TP, Jinnah RH, Clark HJ. The biology of bone grafting. Orthopedics. 1991;14:563-565

48. Wenisch S, Trinkaus K, Hild A, Hose D. Human reaming debris : A source of multi potent stem cells. Bone. 2005; 36:74-83.

49. Hoegel F, Mueller CA, Peter R, Pfister U. Bone debris: dead matter or vital osteoblasts. J Trauma. 2004; 56: 363-370

50. Frolke JP, Nulend JK. Viable osteoblastic potential of cortical reamings from intramedullary nailing. J Orthop Res. 2004; 22:1271-1276.

51. Mark RB, Connor OD. Exchange Nailing of ununited fractures. J Bone Joint Surg Am. 2007; 89:177-189.

52. Pihlajamaki HK, Salminen ST, Bostman OM. The treatment of nonunions following intramedullary nailing of femoral shaft fractures.J Orthop Trauma. 2002;16: 394-403

53. Lin J,Chiang H, Hou SM. Open exchange locked nailing in humeral nonunions after intramedullary nailing. Clin Orthop Relat. Res. 2003; 411: 260268.

54. Silvia R, Cocco LF, Claudio K.Using the wave plate in the treatment of diaphyseal fractures of the femur not consolidated. Minutes Ortop. 2006 ;14:15

55. Mark VP, Archeacon MT. Early rehabilitation following surgical fixation of a femoral shaft fracture. 2006; 86:558-572

56. Christensen NO. Kuntscher intramedullary reaming and nail fixation for non union of fracture of the femur and the tibia. $J$ Bone Joint Surg. 1973;55:312-320

57. Oh I, Nahigian Sh, Rascher JJ, Farrall JP. Closed intramedullary nailing for ununited femoral shaft fractures. Clin Orthop Relat Res. 1975;106:206221

58. Kempf I, Grosse A, Rigaut P. The treatment of non infected pseudarthrosis of the femur and tibia with locked intramedullary nailing. Clin orthop Relat Res. 1986;212:142-154.

59. Wu CC. Shih CH. Distal femoral non union treated with interlocking nailing. J Trauma. 1991;31:16591662

60. Olerud S, Karlstrom G. Secondary intramedullary nailing of tibial fractures. J Bone Joint Surg Am. 1972;54:1419-1428

61. Herper MC. Ununited fractures of the femur stabilized with fluted rod. Clin Orthop Relat Res.1984;190:273-281.

62. Klemm Kw. Treatment of infected pseudoarthrosis of the femur and tibia with an interlocking nail. Clin Orthop Relat Res. 1986; 212:174-181. 
63. Tornetta P III,Tiburzi D. Antegrade or retrograde reamed femoral nailing.J Bone Joint Surg. 2000; 82-B: 652-656.

64. Giannoudis PV, MacDonald DA, Mathews SJ, Smith RM. Nonunion of the femoral diaphysis. J Bone Joint Surg (Br). 2000;82-B:655-663.

65. Wu CC, Chen WJ. Exchange nailing for aseptic nonunion of the femoral shaft. Int. Orthop. 2002;26:80-84.

66. Banaszkiewicz PA, Sabboubeh A, McLeod I, Maffulli N. Femoral exchange nailing for aseptic nonunion: not the end to all problems.Injury. 2003;34:349-356.

67. Wu CC. Exchange nailing for aseptic nonunion of femoral shaft: a retrospective cohort study for effect of reaming size. J Trauma. 2007;63(4): 859865.

68. Sharkar KM. Evalution of Exchange Nailing by SIGN Nail for Femoral Shaft Non union treated by Kuntscher Nail. Thesis; Dhaka university. Jan.2007
69. Heun GJ, Dae JK, Byung HK, Chung YY. Treatment of the femoral shaft nonunion occurred after intramedullary nailing.J Korean Orthop Assoc. 2007;42: 633-658.

70. Susan Standring, Chief editor .Gray`s Anatomy: The Anatomic Basis of Clinical Practice. 39 ed.Edinburgh; Elsevier Churchill Livingstone; 2005;1399-1547

71. McMinn, editor. Last's Anatomy:Regional and Applied. $9^{\text {th }}$ ed. Edinburgh; Churchill Livingstone.1994:145-239

72. Rhineler FW, Phillips R, Steel W, Been J. Microangiography in bone healing. JBJS (Br). 1968;50A:643-662

73. Gustilo RB, KyleRF, Templeman DC. Fracture and dislocations. St.Louis:Mosby;1993

74. Zirkle LG. Technique Manual of I.M nail insertion, extraction and data reporting protocols, Washington: SIGN. 2001, 1-30.

75. Einhorn TA .Enhancement of fracture-healing. J Bone Joint Surg Am. 77:940-956. 